\title{
Osteology and Myology of the Head and Neck of the Pied-Billed Grebes (Podilymbus)
}

BY

RICHARD L. ZUSI AND ROBERT W. STORER

United States National Museum, Washington, D.C., and

Museum of Zoology, University of Michigan, Ann Arbor

ANN ARBOR

MUSEUM OF ZOOLOGY, UNIVERSITY OF MICHIGAN

JULY 24, 1969 


\section{MISCELLANEOUS PUBLICATIONS MUSEUM OF ZOOLOGY, UNIVERSITY OF MICHIGAN}

Francis G. Evans, Editor

The publications of the Museum of Zoology, University of Michigan, consist of two series-the Occasional Papers and the Miscellaneous Publications. Both series were founded by Dr. Bryant Walker, Mr. Bradshaw H. Swales, and Dr. W. W. Newcomb.

The Occasional Papers, publication of which was begun in 1913, serve as a medium for original studies based principally upon the collections in the Museum. They are issued separately. When a sufficient number of pages has been printed to make a volume, a title page, table of contents, and an index are supplied to libraries and individuals on the mailing list for the series.

The Miscellaneous Publications, which include papers on field and museum techniques, monographic studies, and other contributions not within the scope of the Occasional Papers, are published separately. It is not intended that they be grouped into volumes. Each number has a title page and, when necessary, a table of contents.

A complete list of publications on Birds, Fishes, Insects, Mammals, Mollusks, and Reptiles and Amphibians is available. Address inquiries to the Director, Museum of Zoology, The University of Michigan, Ann Arbor, Michigan 48104.

\section{List of Miscellaneous Publications on Birds}

No. 10. A preliminary survey of the bird life of North Dakota. By Norman A.

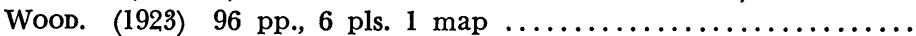

No. 19. The life history of the toucan Ramphastos brevicarinatus. By Josselyn VAN Tyne. (1929) 43 pp., 8 pls., 1 map ................... \$0.75

No. 27. The birds of northern Petén, Guatemala. By Josselyn VAN Tyne. (1935) 46 pp., frontis., 1 pl., 1 map .........................

No. 33. The discovery of the nest of the Colima warbler (Vermivora crissalis). By Josseyln VAN TYNe. (1936) 11 pp., colored frontis., 3 pls., 1 map ..

No. 37. The birds of Brewster County, Texas. By Josselyn Van TyNE and George Mrksch Sutron. (1937) 119 pp., colored frontis., 5 pls., 1 map ....

No. 41. The life history of Henslow's sparrow, Passerherbulus henslowi (Audubon). By A. Sidney Hyde. (1939) 72 pp., 4 pls., 3 figs., 1 map .........

No. 44. The birds of Buckeye Lake, Ohio. By Milton B. Trautman. (1940)

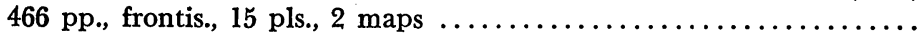

No. 55. Birds from the Gulf lowlands of Southern Mexico. By Pierce Brodkorb.

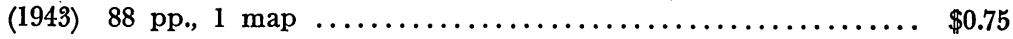

No. 74. Studies of the nesting birds of the Edwin S. George Reserve. Part I. The vireos. By George M. Sutron. (1949) 37 pp., 5 pls. ..............

No. 75. The birds of Michigan. By Norman A. Wood. (1951) 559 pp., 16 pls.,

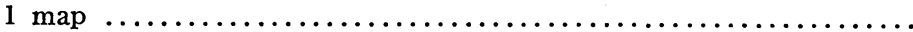

No. 81. A systematic study of the avian family Fringillidae, based on the structure of the skull. By Harrison B. Tordoff. (1954) 42 pp., 77 figs. .....

No. 85. The myology of the pectoral appendage of three genera of American cuckoos. By Andrew J. Berger. (1954) 35 pp., 4 figs. ...........

No. 102. Great blue heron: behavior at the nest By W. Powell Cottrille AND Betty Darling Cottrille. (1958) 15 pp., 7 figs. ..............

No. 125. The breeding biology of the Acadian flycatcher. By Russell E. Mumford.

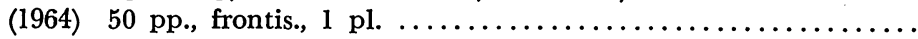

No. 136. The biology of the elf owl, Micrathene whitneyi. By J. David Ligon.

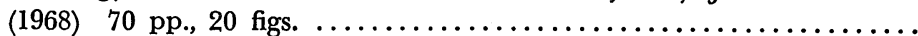

No. 139. Osteology and myology of the head and neck of the Pied-Billed Grebes (Podilymbus). By Richard L. Zusi and Robert W. Storer. (1969)

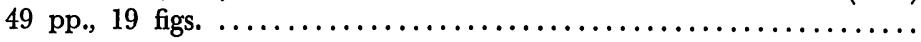




\title{
Osteology and Myology of the Head and Neck of the Pied-Billed Grebes (Podilymbus)
}

\author{
BY \\ RICHARD L. ZUSI AND ROBERT W. STORER \\ United States National Museum, Washington, D.C., \\ and \\ Museum of Zoology, University of Michigan, Ann Arbor
}

ANN ARBOR

MUSEUM OF ZOOLOGY, UNIVERSITY OF MICHIGAN

JULY 24, 1969 



\section{CONTENTS}

PAGE

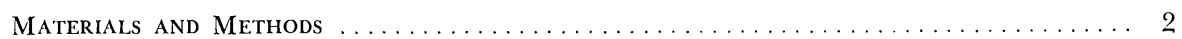

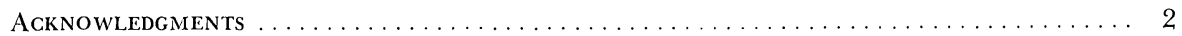

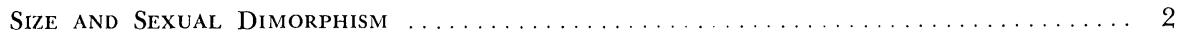

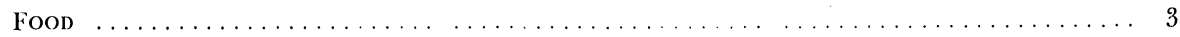

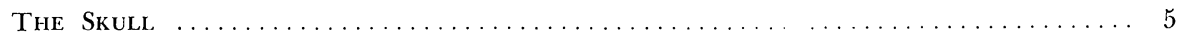

Superficial Ligaments and Aponeuroses of the Skull $\ldots \ldots \ldots \ldots \ldots \ldots \ldots \ldots \ldots \ldots$

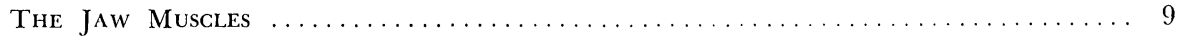

Muscles of the Hyoid Apparatus $\ldots \ldots \ldots \ldots \ldots \ldots \ldots \ldots \ldots \ldots \ldots \ldots \ldots \ldots \ldots$

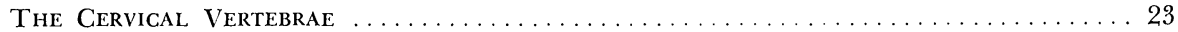

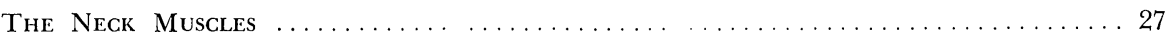

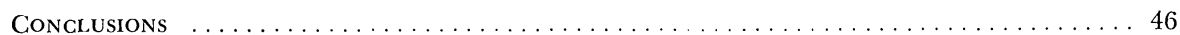

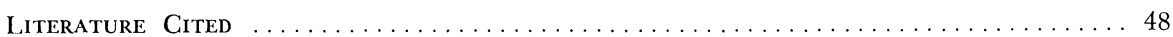




\section{ILLUSTRATIONS}

FIGURE:

PAGE

1. Features of the skull of Podilymbus podiceps $\ldots \ldots \ldots \ldots \ldots \ldots \ldots \ldots$

2. Jaw muscles and ligaments of Podilymbus podiceps $\ldots \ldots \ldots \ldots \ldots \ldots \ldots \ldots \ldots$

3. Ligaments and aponeuroses of the jaw of Podilymbus podiceps ........... 10

4. Deep jaw muscles of Podilymbus podiceps ..................... 13

5. Ventral view of $M$. pterygoideus, pars lateralis and medial view of aponeuroses of

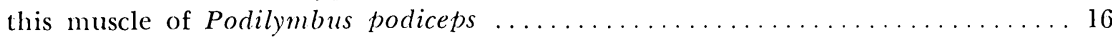

6. Attachments of the jaw muscles of Podilymbus podiceps . . . . . . . . . . 18

7. Hyoid musculature of Podilymbus podiceps $\ldots \ldots \ldots \ldots \ldots \ldots \ldots \ldots \ldots \ldots \ldots$

8. Diagram of cervical vertebrae and functional sections of

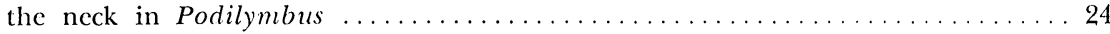

9. Topography of cervical vertebrae of Podilymbus podiceps $\ldots \ldots \ldots \ldots \ldots \ldots$

10. Topography of cervical vertebrae of Podilymbus podiceps . . . . . . . . . . 26

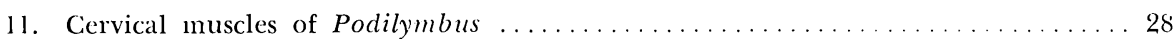

12. Diagram of $M$. complexus in Podilymbus ..................... 29

13. M. reclus capitis superior and M. flexor colli brevis of Podilymbus podiceps .... 30

14. Diagram of $M$. biventer cervicis, Mm. splenii colli, and M. spinalis cervicis

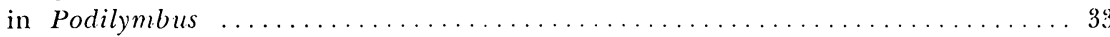

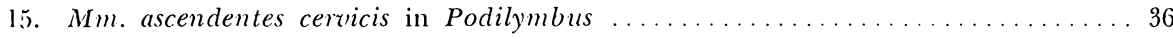

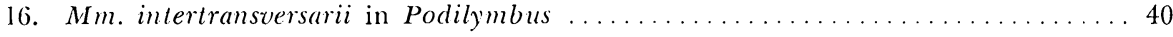

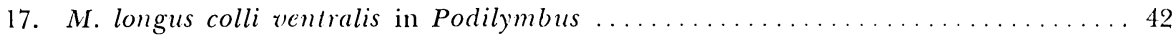

18. Diagram of $M$. flexor colli profundus in Podilymbus ................ 44

19. Attachments of cervical muscles on selected vertebrae $\ldots \ldots \ldots \ldots \ldots \ldots \ldots \ldots \ldots 5$ 


\section{OSTEOLOGY AND MYOLOGY OF THE HEAD AND NEGK OF THE PIED-BILLED GREBES (PODILYMBUS)}

THE ANATOMISTS of the nineteenth century produced several studies of grebes; but their emphasis was on the systematic position of the group, and few species, almost all of them European, were studied. In the New World, the radiation of the family has produced the most divergent types, ranging from the fish-spearing Western Grebe (Aechmophorus occidentalis) to the stout-billed pied-bills (Podilymbus) which include many crustaceans in their diet. In "The Structure and Classification of Birds," which well summarized the field up to the time of its appearance (1898), Beddard noted (p. 386) that "Podilymbus . . . has not been dissected." The same might have been said for the genus Aechmophorus, for at that time knowledge of the anatomy of that genus was based on Beddard's study (1896) of "Aechmophorus" major, a species which has since been shown to be more closely related to Podiceps than to Aechmophorus (Wetmore and Parkes, 1954).

Our first purpose in this paper is to prepare for a comparative study of the head and neck of the grebes by describing in detail the skeleton, ligaments, and muscles of these regions in Podilymbus podiceps. In addition, we have made comparisons of this species with the Giant Pied-bill ( $P$. gigas) and have suggested correlations of the jaw musculature with the food habits of these species.

Since Shufeldt's descriptions of the skulls of grebes $(1890 ; 1904)$, three major papers have treated the head or neck of grebes. Boas included the Great Crested Grebe (Podiceps cristatus) in his monograph on the neck of birds (1929), Hofer included "Podiceps philippinensis" and "P. ruficollis"1 in his treatise (1950) on the jaw musculature of birds, and the as yet unfinished work of Bams (1956) describes the skull and jaw musculature of $P$. cristatus. These papers have been particularly helpful background material for the present work.

\footnotetext{
1 Hofer discusses Podiceps philippinensis and P. ruficollis, illustrating P. philippinensis. Previously, the name philippinensis (or philippensis) has been used only for Tachybaptus ruficollis (terminology of Storer, 1963); the name ruficollis has been used for Tachybaptus ruficollis and Podiceps grisegena. Hofer refers to "the dwarf form $P$. ruficollis and the normal sized $P$. philippinensis," suggesting that by $P$. ruficollis he is referring to Tachybaptus ruficollis, but that the specimen referred to as $P$. philippensis was not Tachybaptus ruficollis. The illustrations are clearly not of $T$. ruficollis, but of one of the larger Podiceps species, probably cristatus or grisegena.
} 


\section{MATERIALS AND METHODS}

Three specimens each of Podilymbus podiceps podiceps and P. gigas were used for the dissections. All were first preserved in ten percent formalin and then stored in ethyl alcohol. Study of the skeleton is based on 42 skeletons of $P$. p. podiceps and 1 of $P$. gigas in the collections of the University of Michigan Museum of Zoology, and comparisons were made with skeletons of 13 other species in the same collections (Tachybaptus ruficollis, Rollandia rolland chilensis, $R$. micropterum, Podiceps dominicus, P. rufopectus, $P$. major, $P$. occipitalis, $P$. taczanowskii, $P$. nigricollis, $P$. auritus, $P$. cristatus, $P$. grisegena, and Aechmophorus occidentalis, nomenclature of Storer, 1963). In addition, we studied two skeletons of $P$. gigas from the collections of the United States National Museum.

The dissections were made by Zusi, who prepared the first draft of the muscle descriptions. Both authors checked the dissections against the descriptions and revised the early drafts. The other parts of the manuscript were largely prepared by Storer and were revised by both authors.

\section{ACKNOWLEDGMENTS}

We are especially indebted to Dr. Laurence C. Stuart for obtaining and preserving the anatomical material of $P$. gigas, without which the comparative aspects of the work would have been impossible. Many of the specimens of $P$. podiceps were confiscated from hunters at the Pointe Mouillee State Game Area, Monroe County, Michigan, where they were saved for us through the courtesy of Leo B. Pospichal, formerly manager of the Area. Base drawings of the neck were expertly prepared by William L. Brudon and several of the figures were rendered by Suzanne Runyan. Figures of hyoid and neck muscles were drawn by Zusi. Dr. Robert R. Miller identified material from the stomachs of our specimens of $P$. gigas and gave us valuable information about the fauna of Lake Atitlán. This study was made possible through the support of the National Science Foundation (Grants G-4846 and GB-575 to Storer).

\section{SIZE AND SEXUAL DIMORPHISM}

The Pied-billed Grebe is divided into three subspecies, a small West Indian race (antillarum), a large South American race (antarcticus), and the nominate North American race, which is intermediate in size. Comparisons have been made only between $P$. gigas and the nominate podiceps.

Sexual dimorphism is marked in these birds (Table 1). The males average ten percent larger than the females in tarsal length (Table 2) and apparently also in cranial length (only three gigas skeletons are available). 
Sexual dimorphism in culmen length and bill depth are probably not significantly different from that in tarsal length (Table 2). Comparing the species on a sex-for-sex basis (Table 3), we find a 14 to 15 percent difference in tarsal length but a significantly greater difference in bill depth. Thus gigas is a somewhat larger bird than podiceps and has a relatively heavier bill.

TABLE I

Measurements of Pied-billed Grebes (Podilymbus podiceps and P. gigas) in millimeters

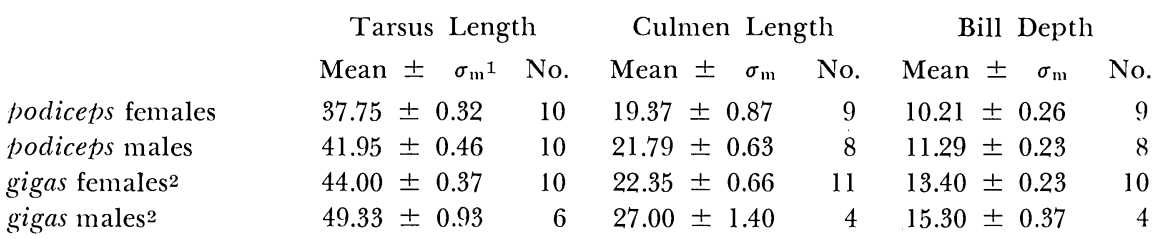

iStandard error of the Mean

In preparing these Tables 1-3, the following specimens of gigas were assumed to be missexed: Mus. Comp. Zool. 147,290, “ $₫$ ” wing, $126 \mathrm{~mm}$., tarsus, $44.8 \mathrm{~mm}$., culmen, 22.3 mm.; M.C.Z. 147,291, “o”, 125, 44.7, $22.7 \mathrm{~mm}$.; and M.C.Z. 147,292, “o”, 141, 49.8, 27.7 $\mathrm{mm}$; and the following were sexed on the basis of measurements: Brit. Mus. 93-2-1-886. wing, 130, tarsus, $46.0 \mathrm{~mm}$. = ; B. M. $92-1-20-22,137,48.0 \mathrm{~mm} .=\hat{\delta}$; and M.C.Z. 145,692 , wing, 140, bill depth, $16.0 \mathrm{~mm} .=\hat{\delta}$.

TABLE 2

Sexual Dimorphism in Podilymbus podiceps and $P$. gigas. The difference between the MEAN MFASUREMENTS FOR THE SEXES EXPRESSED AS PERCENT OF THAT FOR THE MALE.

$\begin{array}{lccc} & \text { Tarsal Length } & \text { Culmen Length } & \text { Bill Depth } \\ \text { P. podiceps } & 10.0 & 11.1 & 9.6 \\ \text { P. gigas } & 10.7 & 17.2 & 12.4\end{array}$

\section{FOOD}

In North America, Pied-billed Grebes are known to eat a wide variety of animals, being quick to take advantage of almost any readily available source of food. However, reports of their food by Wetmore (1924), Munro (1941), Gabrielson (1914), R. F. Miller (1943), and Trautman (1940) indicate that they eat a considerably larger proportion of crayfish and frogs than do the other North American grebes. Pied-bills, with their stout bills and heavy jaw musculature, are well adapted for killing crayfish, as well as heavy-bodied fish and frogs. Wetmore (1924:20-21) presents the following evidence for the use of the bill in preparing food for swallowing: "It was interesting to note the thorny pectoral and dorsal spines of the channel cat [Ictalurus punctatus] had been broken, apparently before the fish had been 
TABLE 3

The Difference between Mean Measurements for $P$. podiceps and $P$. gigas expressed AS PERCFNT OF THOSE FOR $P$. gigas

$\begin{array}{lccc} & \text { Tarsal Length } & \text { Culmen Length } & \text { Bill Depth } \\ \text { Males } & 15.0 & 19.3 & 26.2 \\ \text { Females } & 14.2 & 13.3 & 23.8\end{array}$

swallowed. . . C Crawfishes $31 / 2$ inches long often were found and from their appearance and position in the stomach had been swallowed tail foremost. In the larger individuals the claws had been sheared off near the body before the animals were swallowed."

Nothing appears to be known of the food of the Pied-billed Grebe in Central and South America. Through much of its range in the American tropics, crayfish are absent (as they are in much of the Canadian prairies, where the Pied-bills also nest). In these areas where crayfish are absent, other crustaceans, fish, frogs, and insects must make up larger proportions of the diet than they do in most of North America.

The Giant Pied-bill is confined to Lake Atitlán in the highlands of Guatemala. The only reports of its food are those of Bowes and Bowes (1962:708), who observed examples of the species securing "small fish and possibly some aquatic vegetation" and who mention that Jorge Ibarra, Director of Guatemala's Museum of Natural History, wrote them of finding a fish (Cichlasoma nigrofasciatum) in the stomach of a Giant Pied-bill; and Bowes (1965:15-16), who describes the feeding behavior of the species and reports the stomach contents of four specimens as "small fish . .., balls of feathers, pebbles (one of pumice), a snail $(11 / 2 \mathrm{~cm}$.), and insect remains." Storer examined the stomach contents of the three preserved specimens which Dr. Stuart obtained and found the remains of a fish, identified as Mollienesia sphenops or M. mexicana by Dr. Robert R. Miller, plus a few scales and bones of other small fish, bits of chitin, and many feathers.

Owing to the paucity of information on the diet of the Giant Pied-bill and to the fact that the two species of fish on which it has been found to feed were probably introduced into the lake by man, we must seek indirect evidence concerning the evolution of the Giant Pied-bill in relation to its food. No endemic species of fish are known from Lake Atitlán, and according to R. R. Miller (1955:20) “it may be questioned whether Lake Atitlán has contained any native fishes since its origin." However, a crab, Potamocarcinus guatemalensis, is abundant in the lake (Saunders et al., 1950:109). Thus in this lake, there appears to have been a special niche for a crabeating diver. It is hardly surprising, therefore, that the heavy-billed $P$. gigas should have evolved to fill this niche. 
THE SKULL (FIG. 1)

The skull of Podiceps cristatus has been figured and described by Bams (1956). That of Podilymbus differs markedly from it in having a much shorter, heavier bill with a curved culmen. The palatines are more expanded laterally, and the vomer, instead of ending as a fine point, terminates in a disc-like plate, as mentioned by Shufeldt (1904:17). In Podilymbus, the brain case is less narrowed and less elongated posteriorly than in P. cristatus, and the temporal fossa is correspondingly less deep. Crest $\mathrm{C}$, on the posterior border of this fossa is much less pronounced in Podilymbus. The postorbital process (Processus temporalis of Bams) lies further anteriorly, almost on the rim of the orbit, and it is separated by several millimeters from the attachment of Aponeurosis X (on Crest E), which in P. cristatus, lies adjacent to and just ventral to that process. The crest running vertically down the middle of the area of origin of $M$. pseudotemporalis superficialis in $P$. cristatus is not found in Podilymbus.

The mandible of Podilymbus is correspondingly shorter and stouter than that of $P$. cristatus. The posterior end is cut off more vertically so that the posterior face, which forms the area of insertion of $M$. depressor mandibulae, lies nearly in a transverse plane, whereas in $P$. cristatus this face lies posterodorsally. The rami of the lower jaw in Podilymbus show considerable capacity for lateral bowing through bending of the flexible regions near the short symphysis and at the posterior edge of the dentary.

Both species of Podilymbus show well-developed kinetic features of the skull. Free motion of the upper jaw above and below its resting position is permitted by its flexible attachments to the cranium above and to the palate and jugal bars below. The vomer and palatines fuse to form a trough that grips the tubular rostrum and allows free sliding of the palate. The jugal bars are very slender and laterally compressed and the force of protraction of the upper jaw is therefore probably transmitted chiefly through the pterygoid and palatine bones. (Kinesis in grebes is also discussed by Simonetta [1963].)

\section{SUPERFICIAL LIGAMENTS AND APONEUROSES OF THE SKULL (FIGS. 2, 3)}

P. podiceps.-Deep to the skin and fascia of the side of the head is a tough aponeurotic sheet that surrounds the eye opening and covers part of the jaw musculature. It extends from the dorsal rim of the orbit to the jugal bar and from the prefrontal bone to the postorbital ligament. Portions of this sheet are particularly well developed and have been described as ligaments in other species (see Barnikol, 1952). The anterodorsal portion 

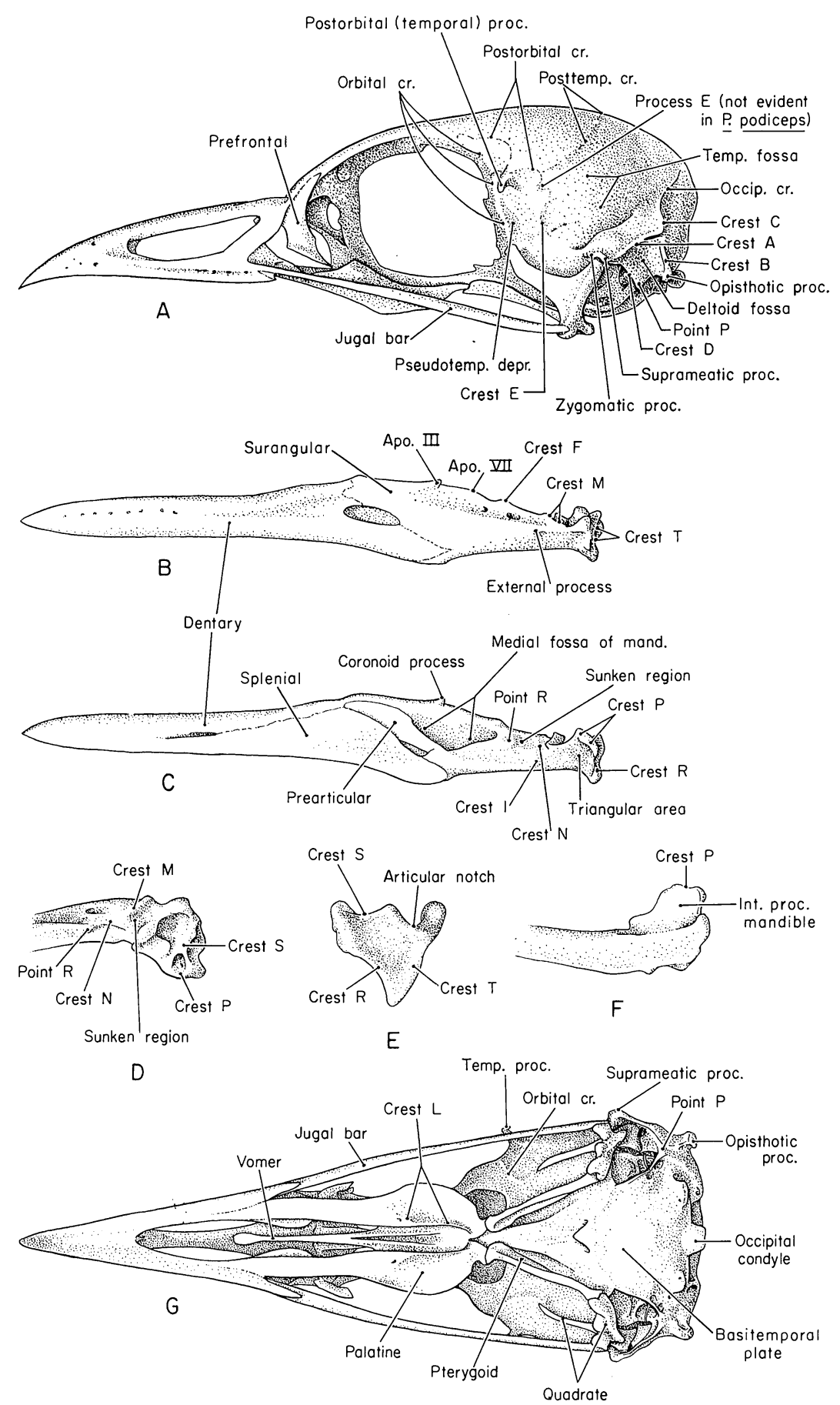

Fig. 1. Features of the skull of Podilymbus podiceps. A. Skull, lateral view. B. Mandible, lateral view. C. Mandible, medial view. D. Mandible, dorsal view of posterior end of right ramus. E. Mandible, posterior view of articular of right ramus. F. Mandible, ventral view of posterior end of right ramus. G. Skull, ventral view. Abbreviations: Apo.Aponeurosis, cr.-crest, depr.-depression, int.-internal, mand.-mandible, occip.-occipital, posttemp.-posttemporal, proc.-process, pseudotemp.-pseudotemporal, temp.-temporal. 

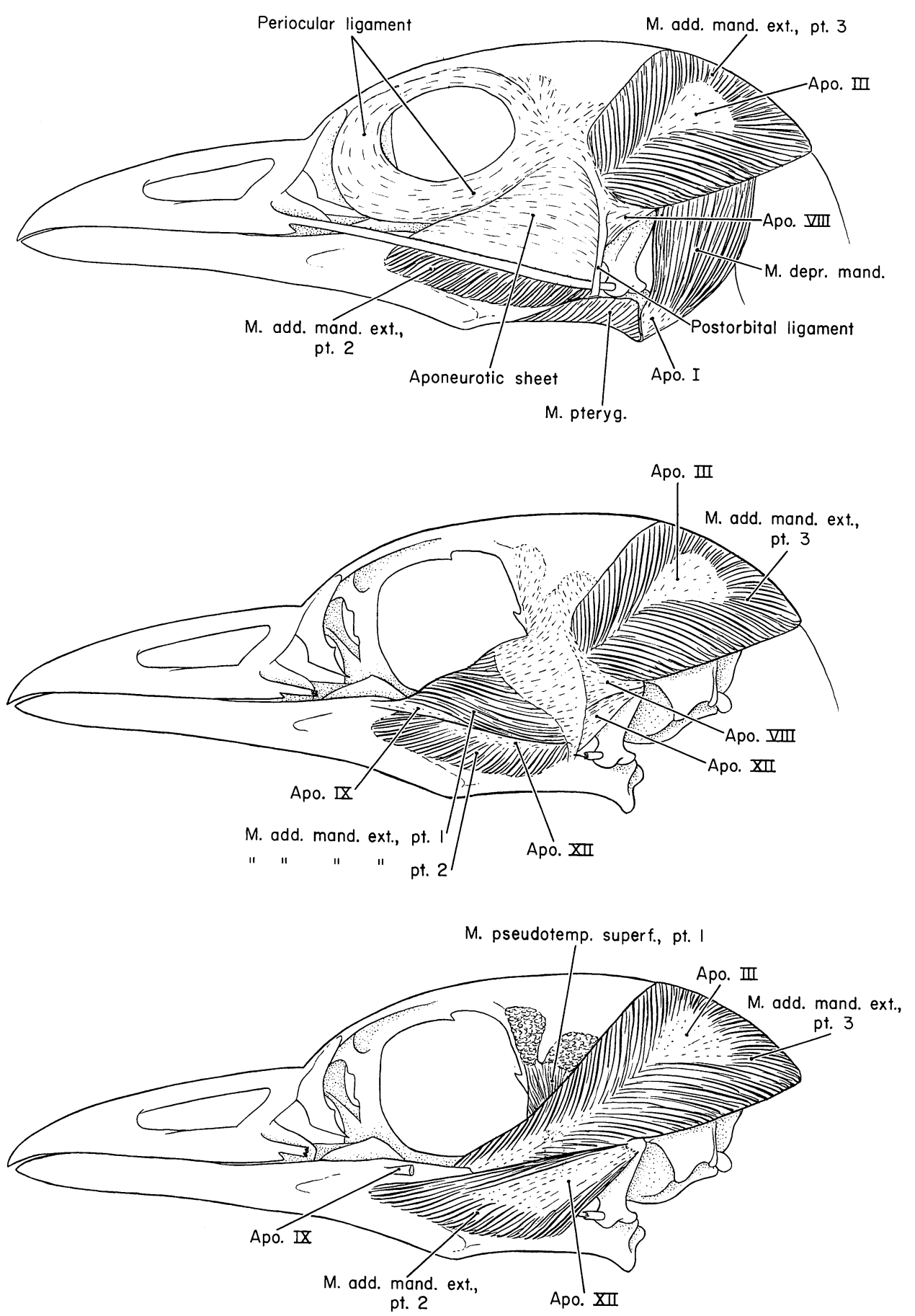

FIg. 2. Jaw muscles and ligaments of Podilymbus podiceps. Top-skin removed. Middleaponeurotic sheet, periocular ligament, jugal bar, $M$. depressor mandibulae and $M$. pterygoideus removed. Bottom-M. adductor mandibulae externus part 1 , and aponeurotic sheet covering $M$. pseudotemporalis superficialis pt. 1, removed. Abbreviations: add.-adductor, Apo.-Aponeurosis, depr.-depressor, ext.-externus, M.-Musculus, mand. -mandibulae, pseudotemp.-pseudotemporalis, pt.-part, pteryg.-pterygoideus, superf,superficialis, 
forms the periocular ligament which encircles the eye, attaching strongly to the postorbital process posteriorly and the dorsal and ventral portions of the prefrontal bone anteriorly. The dorsal portion of this ligament is continuous with a thinner sheet that overlies the dorsolateral portion of M. pseudotemporalis superficialis and encloses the supraorbital glands. It attaches along the supraorbital rim of the frontal bone anteriorly as far as the prefrontal. The periocular ligament has a loose and fatty attachment with the middle portion of the prefrontal between the dorsal and ventral attachments to that bone. Ventrally the periocular ligament continues as a tough aponeurotic sheet covering $M$. adductor mandibulae externus, Part 1, and attaches along the lateral surface of the jugal bar by tough fascia which becomes thinner and weaker posteriorly. This attachment extends posteriorly as far as the postorbital ligament.

Extending forward and fanning out from the zygomatic process is an aponeurosis (VIII) which underlies part of the aponeurotic sheet just described and fuses with it over M. adductor mandibulae externus, Part 1. The postorbital ligament runs posteroventrally from the postorbital process to a point anterior to the zygomatic process where it is fused with the underlying Aponeurosis VIII. From this point the postorbital ligament loses its attachment to underlying tissues and runs ventrally to its attachment on the external process of the mandible. It passes lateral to the jugal bar and to the external jugo-mandibular ligament.

The external jugo-mandibular ligament is a stout, strap-like ligament running anteroventrally, from the posterolateral surface of the jugal bar close to the latter's articulation with the quadrate, to the external process of the mandible medial to the attachment of the postorbital ligament.

The articular jugo-mandibular ligament is a stout, strap-like band attaching to the posteroventral edge of the jugal bar and running posteriorly, lateral to the articulation of the quadrate with the lower jaw and then medially to attach on the medial rim of the articular notch. Its internal surface is sculptured in such a way as to fill the space between the lateral parts of the articulating condyles of the quadrate and the lower jaw. It is tightly bound by connective tissue to the lateral and posterior condyles of the quadrate. (In Podilymbus no sesamoid bone is developed in this ligament.)

$P$. gigas.-These ligaments and aponeuroses are similar to those of $P$. podiceps except that the aponeurotic sheet enclosed by the periocular ligament, postorbital ligament, and jugal bar is thinner in gigas. The aponeurotic sheet extends farther posteriorly in gigas, covering the anterodorsal superficial portion of $M$. adductor mandibulae externus, Part 3, posterior to the postorbital ligament and all exposed parts of $M$. pseudotemporalis superficialis. 
THE JAW MUSCLES (FIGS. 2-6)

In most respects, we have followed Lakjer's (1926) nomenclature of the jaw muscles. The two principal exceptions are our treatment of $\mathrm{Mm}$. protractor quadrati et pterygoidei as a single muscle and our somewhat different subdivision of $M$. adductor mandibulae externus. As Lakjer reported only on the muscles innervated by the Trigeminal Nerve, he did not include $M$. depressor mandibulae in his study. Our names for muscles, but not necessarily their subdivisions, correspond also to those used by Hofer (1950), except that we use $M$. pseudotemporalis profundus for his $M$. quadratomandibularis.

In so far as possible, we have followed Bams' (1956) nomenclature of the aponeuroses, and to a lesser degree, his naming of the crests on the skull. Bams' names for jaw muscles are compared with ours in Table 4.

Unless otherwise indicated, the descriptions apply to $P$. podiceps; comparison with the condition in $P$. gigas follows the detailed sections on podiceps.

M. depressor mandibulae (Figs. 2, 3, 6) is a broad, thick muscle lying posterior to the ear opening. Its fibers originate on the skull from the entire surface of the deltoid fossa and from Crests A and B, which form, respectively, the anterodorsal and posterior borders of this fossa.

TABLE 4

Synonymy of Muscles of The JaW in Grebes

Present paper

M. adductor mandibulac externus

M. adductor mandibulae posterior

M. pseudotemporalis profundus

M. pseudotemporalis superficialis

M. protractor quadrati et pterygoidei

M. pterygoideus

a) pars lateralis, dorsolateral branch

b) pars lateralis, ventromedial branch

c) pars dorsalis, lateral branch

d) pars dorsalis, medial branch
Bams (1956)

M. adductor mandibulae externus et posterior

M. adductor mandibulae externus profundus, caudal part

M. adductor mandibulae externus profundus, rostral part

M. adductor mandibulae internus pseudotemporalis superficialis

Mm. protractor quadrati et pterygoidei

M. adductor mandibulae internus pterygoideus

pars lateralis, dorsolateral branch pars lateralis, ventromedial branch (part)

pars dorsalis

pars lateralis, ventromedial branch (part) 
In addition, fibers arise from a short aponeurosis attaching along Crest $A$ and the adjacent portion of Crest C. A few fibers arise from the lateral surface of the aponeurosis of $M$. rectus capitis lateralis which attaches on Crest B ventrally. An aponeurosis (II) arising from Crest D and the adjacent occipitomandibular ligament serves as origin for the deeper fibers of this muscle. The occipitomandibular ligament (PQ of Bams) extends from the posteroventral corner of the deltoid fossa (Point $\mathrm{P}$ ) to the transverse crest (Crest S) of the articular bone medial to the articular notch. Aponeurosis II runs along the posterior side of the ear opening and is loosely bound to the lining of that opening. The insertion of fibers from Aponeurosis II fills the entire posterior depression of the articular bone. Most of the fibers from the deltoid fossa and Crests A, B, and C insert on the inner surface of a superficial aponeurosis (I) attached to the posteroventral tip of the articular and extending halfway up the lateral and medial crests which border the depression. There is a poorly developed internal fold running dorsoventrally along this aponeurosis.

In addition to the occipitomandibular ligament, which is near the medial edge of Aponeurosis II, there is a thin ligament along the lateral edge of this aponeurosis. This ligament runs from near the anterior end of Crest D to the posterolateral edge of the articular, where it inserts on a small process immediately below the articular notch.

This muscle is similar in $P$. gigas, but no ligament was found along the lateral edge of Aponeurosis II in two specimens.

M. adductor mandibulae externus (Figs. 2, 3, 6) is partially covered by superficial aponeuroses. We consider it made up of three parts although the division is not complete. In general, we assign fibers inserting on

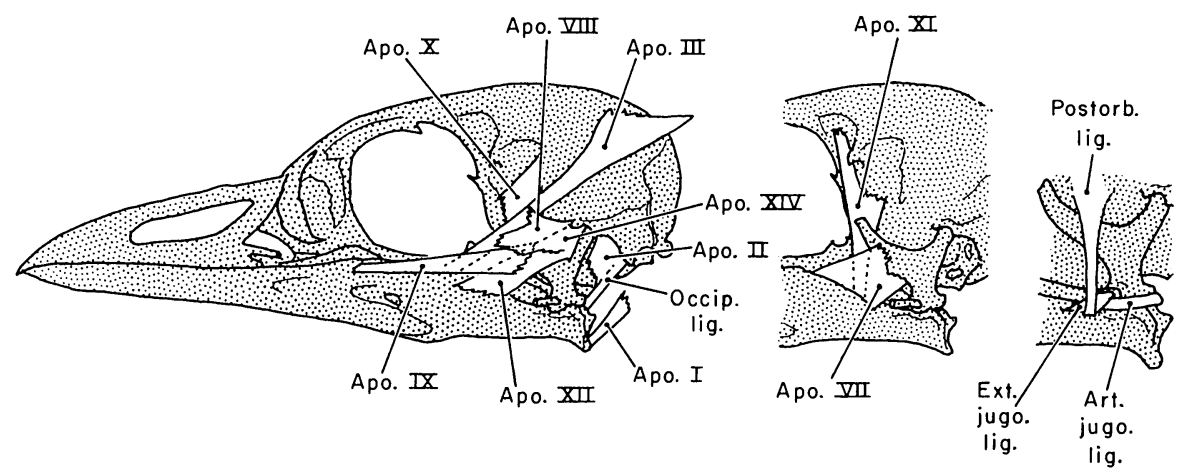

Fig. 3. Ligaments and aponeuroses of the jaw of Podilymbus podiceps. Jugal bar and fleshy fibers of all jaw muscles removed. Abbreviations: Apo.-Aponeurosis, Art.-Articular, Ext.-External, jugo.-jugomandibular, lig.-ligament, Occip.-Occipitomandibular, Postorb.-Postorbital. 
Aponeurosis IX to Part 1, those inserting on Aponeurosis VII and the lateral surface of the mandible to Part 2, and those inserting on Aponeurosis III to Part 3.

Part 1 is a flat, triangular muscle lying immediately beneath the superficial aponeuroses posteroventral to the eye. Its fibers insert on the medial and lateral surfaces of a well developed aponeurosis (IX) that narrows to a flat tendon inserting on the dorsolateral face of the dentary at its junction with the surangular. The dorsal fibers arise from the inner face of the postorbital ligament and of the aponeurotic sheet extending forward from it; the ventral fibers arise from the inner faces of Aponeurosis VIII and the aponeurotic sheet, from the lateral surface of Aponeurosis XIV deep to the ventral portion of Aponeurosis VIII, and from the adjacent parts of Aponeurosis XII. A few fibers arise from the lateral surface of Aponeurosis III.

In $P$. gigas, this part is similar, but relatively better developed. The tendon of Aponeurosis IX is partially hidden by fibers of Part 2. The anterdorsal edge of Aponeurosis IX fuses in part with the anterior edge of Aponeurosis III.

Part 2 is a fan-shaped muscle, partially deep to Part 1. It arises from a strong aponeurosis (XII) attached to the zygomatic process. A small aponeurosis (XIV) from the dorsal end of the otic process of the quadrate fuses with Aponeurosis XII. The muscle fibers run from the medial surface of the two aponeuroses (XII and XIV) to attach on the lateral surface of the mandible (most of the lateral surface of the surangular-see Fig. 6C), and on the lateral suface of Aponeurosis VII. Some muscle fibers come directly from the zygomatic process and adjacent portions of the temporal fossa at which point they are not clearly separable from fibers of Part 3. Fibers from the posteroventral portion of Aponeurosis $\mathrm{X}$ inserting on the medial surface of Aponeurosis VII are included in this part, whereas the remaining fibers from the lateral surface of Aponeurosis X inserting on Aponeurosis III are included in Part 3. Fibers from Aponeurosis XII that insert along the posterior edge of Aponeurosis III are included here although they merge with the fibers of Part 3.

In $P$. gigas Part 2 is similar but relatively better developed.

Part 3 is the large superficial muscle of the back of the head. It originates from the temporal fossa and the rather extensive aponeurotic surface of $M$. complexus. Some fibers of the right and left muscles attach on a median raphe extending from the posterior end of the posttemporal crest back to the posterior end of the aponeurosis on $M$. complexus. Fibers also originate from the anterolateral surface of a thin, sheetlike aponeurosis (X) springing from Crest $\mathrm{E}$. The principal insertion is by a strong tendon 
to the coronoid process of the surangular. As it runs posterodorsally from its attachment on the mandible, this tendon fans out gradually into an aponeurosis (III) which curves toward the median raphe. This aponeurosis is superficial as a triangular area ending about $1 \mathrm{~cm}$. from the median raphe (Fig. 2). The superficial fibers from the median raphe and from either side of the temporal fossa insert on the lateral surface of Aponeurosis III around the exposed triangular portion. The remaining fibers from the temporal fossa, the median raphe, and the surface of $M$. complexus insert on the medial surface of Aponeurosis III, with the exception of some fibers from the anteroventral part of the temporal fossa near the postorbital process, and from the dorsal surface of the zygomatic process and of Crest $\mathrm{A}$, which converge in pennate fashion on the lateral surface of Aponeurosis III. Fibers from the anterodorsal surface of Aponeurosis X insert on the medial surface of Aponeurosis III and on a thin aponeurotic extension of its anterodorsal edge. Fibers from the remaining lateral surface of Aponeurosis $\mathrm{X}$, and from the deep portion of the temporal fossa near the zygomatic process insert on the medial surface of Aponeurosis VII. These fibers are arbitrarily assigned to Part 2.

In $P$. gigas this muscle is more powerfully developed. Aponeurosis III is a strong tendon from its insertion well back into the temporal fossa. The tendon bears a dorsolateral ridgelike aponeurotic extension which disappears posteriorly at the point where the main tendon fans out to become a sheet. This sheet is mostly superficial in $P$. podiceps, but in $P$. gigas both of its surfaces are completely occupied by inserting muscle fibers. Those which insert on its lateral face arise from the periphery of the posterodorsal area of origin-along the posttemporal crest, the dorsal edge of the median raphe, and the posterior end of the aponeurosis of $M$. complexus. The anterodorsal portion of Aponeurosis $\mathrm{X}$ is thicker and longer than the posteroventral portion and it springs from a well defined process (E) lacking or less prominent in $P$. podiceps.

$M$. adductor mandibulae posterior (Figs. 4, 6) is a short, rather stout, fleshy muscle running between the quadrate and the lower jaw. Its anterior limits are separated from $M$. pseudotemporalis profundus by the pterygoid ramus of the trigeminal nerve. Posteriorly, the fibers are adjacent to those of $M$. adductor mandibulae externus, Part 2, arising from the quadrate. The superficial fibers of $M$. adductor mandibulae posterior are separated in part from those of $M$. adductor mandibulae externus by Aponeurosis VII. M. adductor mandibulae posterior arises from the lateral and rentral surfaces and the ventromedial edge of the orbital process of the quadrate. The lateral fibers run ventrally and somewhat anteriorly to their insertion; deeper fibers run posteroventrally. The insertion is on a 

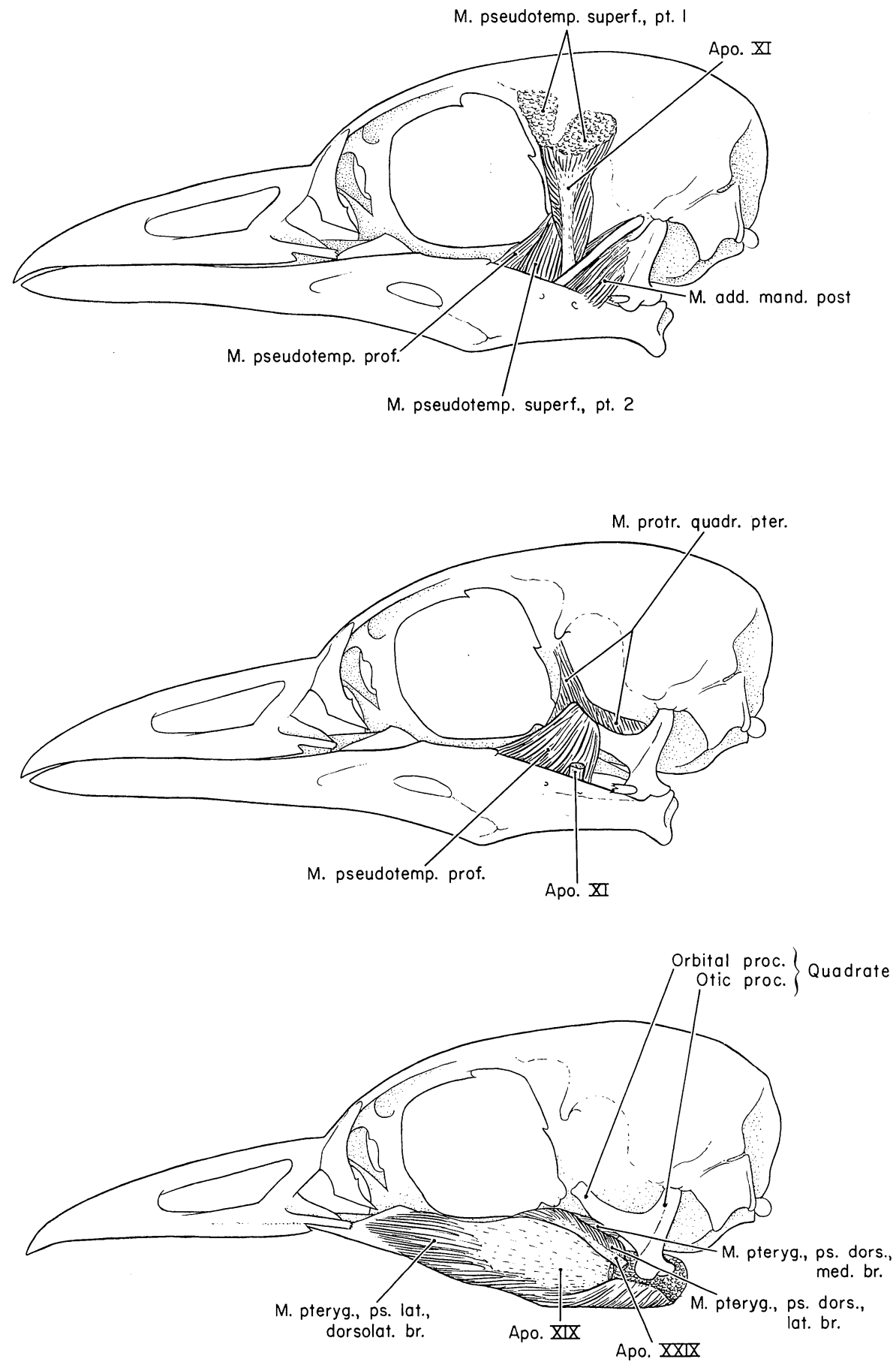

Fis. 4. Deep jaw muscles of Podilymbus podiceps. Lower jaw removed from bottom figure leaving $M$. pterygoideus in natural position. Abbreviations: add.-adductor, Apo.Aponeurosis, br.-branch, dorsolat.-dorsolateral, dors.-dorsalis, lat.-lateralis, M.-Musculus, mand.-mandibulae, med.-medial, post.-posterior, proc.-process, prof.-profundus, prot.-protractor, ps.-pars, pseudotemp.-pseudotemporalis, pt.-part, pter.-pterygoidei, pteryg.-pterygoideus, quadr.-quadrati, superf.-superficiạlis, 
groove in the posterodorsal surface of the mandible bounded anteriorly by Crest $\mathrm{F}$ and posteriorly by the jaw articulation, and on the adjacent dorsomedial surface of the mandible. The insertion is fleshy. Some inserting fibers of $M$. pterygoideus, pars dorsalis (of Bams) are bound by connective tissue to the medial fibers of this muscle.

In $P$. gigas, this muscle is similar.

M. pseudotemporalis profundus (Figs. 4, 6) is an almost entirely fleshy muscle running from the anterior part of the orbital process of the quadrate to the medial surface of the lower jaw. Its origin is from the lateral and medial surfaces of the anterior half of the orbital process of the quadrate. Two small aponeuroses, one from the distal edge of the orbital process (Aponeurosis XVIII of Bams) and one from the ventral edge of the orbital process near its distal end (not described by Bams), are buried in the belly of the muscle, all of their surfaces serving for the attachment of muscle fibers. The first of these small aponeuroses (XVIII) is directed somewhat forward and is contained in the anterior part of the belly; the second is directed almost ventrally and lies within the central part of the belly. The insertion fills the ventral part of the medial fossa of the mandible (canalis primordialis of Bams) and the well-defined depression posteroventral to the fossa, extending posteriorly below and partly around Point R to Crest I. (See Figs. 1, 6.) Some fibers also attach on the medial surface of the prearticulars (complementary of Bams) immediately anteroventral to the medial fossa of the mandible.

In $P$. gigas, this muscle is similar except that the two small aponeuroses of origin are not separable and are represented by only a few tendinous fibers.

M. pseudotemporalis superficialis (Figs. 2, 3, 4, 6) lies in the posterolateral part of the orbit and runs vertically to the inner surface of the lower jaw. It is superficial dorsally but is covered by $M$. adductor mandibulae externus ventrally and is separated from that muscle by a bundle of nerves from the trigeminal group. In Podilymbus it is composed of two parts, the fibers of which are not readily separable except at their insertions.

Part 1 originates from the anterolateral wall of the cranium. The origin is bounded anteromedially by the orbital crest, dorsally by the postorbital crest, and ventrally by Part 2 and by the origin of $M$. protractor quadrati et pterygoidei. In addition to the origin from the cranium, fibers originate from the inner surface of the superficial aponeurotic layer (= Aponeurosis VI of Bams?) which covers the dorsal portion of the muscle. The fibers converge on a superficial aponeurosis (XI); most of them attach to its inner surface, but a few peripheral fibers attach on its edge externally. 
The dorsal end of the aponeurosis divides into two arms (in a Y-shape), the longer, anterior arm supplying that portion of the muscle anterior to the postorbital process and the shorter, posterior arm supplying the portion posterior to the process. The aponeurosis narrows to a stout tendon which inserts on Point $\mathrm{R}$ on the medial face of the mandible. This part of the muscle corresponds to $M$. adductor mandibulae internus pseudotemporalis superficialis of Bams.

Part 2 is almost entirely fleshy. It is a rather broad, flat muscle partially covered by Part 1. It originates from the orbital wall of the cranium in the pseudotemporal depression between Part 1 and the origin of $M$. protractor quadrati et pterygoidei. The fibers run anteroventrally to insert in a narrow line on the dorsomedial surface of the surangular anterior to the insertion of the tendon of Part 1 (Aponeurosis XI) and deep to the attachment of Aponeurosis VII, and also on a thin lateral aponeurosis which attaches adjacent to Aponeurosis VII.

In $P$. gigas, both parts closely resemble those of $P$. podiceps.

M. protractor quadrati et pterygoidei (Figs. 4, 6) is a stout muscle running from the ventral part of the orbital wall to the medial surface of the quadrate and the posterior end of the pterygoid. Its fleshy origin extends anteriorly to and part way around the opening for the optic nerve, dorsally to the ventromedial portion of the orbital crest and the origin of $M$. pseudotemporalis superficialis, Part 2, posteriorly almost to the zygomatic process, and ventrally to the sphenoidal rostrum. The fibers converge to a well defined fleshy insertion in a depression on the medial side of the body of the quadrate and for a short distance out onto the orbital process. Fibers also attach on a well developed superficial ventrolateral aponeurosis (Aponeuroses XV and XIII of Bams) which inserts on a crest on the anteroventral surface of the body of the quadrate and on the posteroventral edge of the orbital process. The aponeurotic attachment continues dorsally onto the medial surface of the orbital process, outlining the anterior edge of the fleshy insertion. The more anteroventral fibers of this muscle attach on an aponeurosis (XVII) that is separate from $\mathrm{XV}$ only at its insertion on the posterior process of the pterygoid bone.

Bams divides the aponeurosis of insertion of this muscle into two parts although stating (p. 225) that they are continuous. His Aponeurosis XVII attaches to the pterygoid; his Aponeurosis XV to the quadrate. The ventral part of the muscle originating from near the sphenoidal rostrum and running to the process of the pterygoid probably represents $M$. protractor pterygoidei of other birds. In Podilymbus, this muscle and $M$. protractor quadrati are completely fused except at their insertion.

In $P$. gigas, the muscle is similar. 
M. pterygoideus (Figs. 2, 4, 5, 6) is a stout muscle running from the palatine and pterygoid bones to the posterior end of the lower jaw. Bams divides this muscle in $P$. cristatus into two parts: a pars doralis and a pars lateralis; the latter he subdivides into a dorsolateral branch and a ventromedial branch. In $P$. podiceps, the pars dorsalis is also divisible into a lateral and a medial branch.

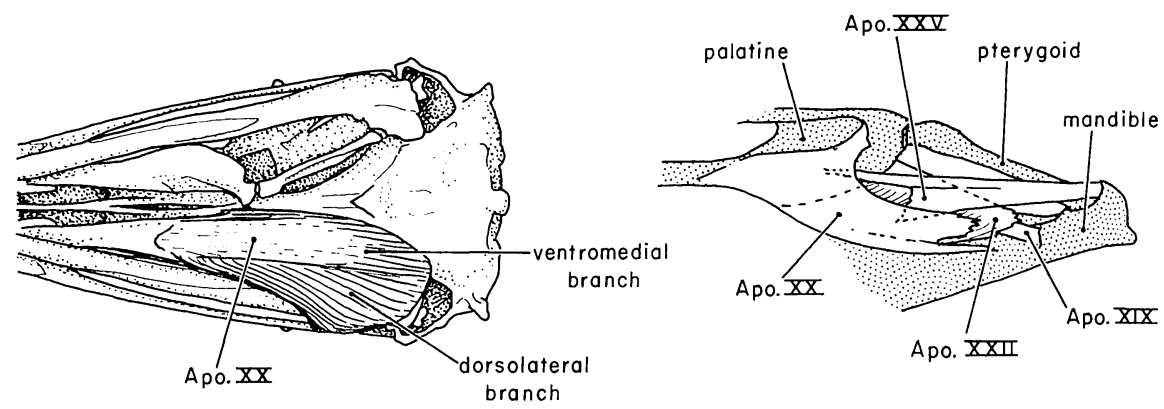

Fig. 5. Left, ventral view of $M$. pterygoideus, pars lateralis of Podilymbus podiceps (left muscle removed); right, medial view of aponeuroses of $M$. pterygoideus, pars lateralis (diagrammatic). Abbreviations: Apo.-aponeurosis.

Pars lateralis, dorsolateral branch arises from most of the dorsolateral surface of the palatine and from the dorsal surface of the extensive aponeurosis (XXII) attaching to the posterolateral edge of the palatine. A ventrolateral extension of the anterior portion of Aponeurosis XXII (from the line of junction between Aponeuroses XX and XXII) provides a further area of origin. Fibers from this branch insert on the medial surface of a strong aponeurosis (XIX), which attaches to Crest I on the medial face of the lower jaw just anterior to the jaw articulation and on the entire posteromedial surface (triangular area of Bams) of the lower jaw between Crests I and R. Fibers also insert on the ventral and ventrolateral surfaces of the lower jaw adjacent to the triangular area (Figs. 1, 6).

The ventromedial branch of pars lateralis arises from the entire ventral cavity of the posterior expanded portion of the palatine lateral to Crest $\mathrm{L}$ (of Bams) and from the ventral surface of Aponeurosis XXII and the dorsal surface of Aponeurosis XX which arises from Crest L. Aponeuroses XX and XXII are fused in their anterolateral portion but they are separate posteriorly. The fibers from this branch insert on a large aponeurosis, XXV (includes Aponeuroses XXI, XXIII, and XXV of Bams?), which is composed of two wings meeting approximately at right 
angles. One wing lies horizontally along the dorsal surface of this muscle. The other extends vertically downward from the lateral edge of the first and enters the body of the muscle. The posterodorsal surface of the horizontal part serves as the insertion of fibers from the medial branch of pars dorsalis. Fibers coming from the more medial portion of the origin insert on the ventral surface of the horizontal wing and on the medial surface of the vertical wing. The fibers from the lateral portion of the origin insert on the lateral surface of the vertical wing. The aponeurosis inserts along the medial edge of the articular bone (Crest P), and a few fleshy fibers attach directly on the ventromedial surface of the articular bone between the attachment of this large aponeurosis and that of the fibers of the dorsolateral branch of this muscle.

Pars dorsalis, lateral branch, has a fleshy origin from the entire lateral surface of the pterygoid bone and from the adjacent ventral edge of the bone. Its fibers converge on the posteromedial surface of a superficial aponeurosis (XXIX), which becomes a stout tendon and inserts on the tip of a crest $(\mathrm{M})$ on the dorsal surface of the mandible slightly anterior to the jaw articulation. Some fleshy fibers insert directly on the dorsal surface of the mandible between the insertion of Aponeurosis XXIX and the jaw articulation (= s. r. of Bams, Fig. 9b left, not $9 \mathrm{~b}$ right!).

The medial branch of pars dorsalis originates from the entire ventral and ventromedial surfaces of the pterygoid, except for the posterior few millimeters of the bone. Part of it also arises from the medial surface of a weak aponeurosis (apparently absent in P. cristatus, Bams) attached to the edge of the dorsal crest of the pterygoid. The fibers run almost straight posteriorly to insert on the posterodorsal surface of the horizontal wing of the aponeurosis of insertion of pars lateralis, ventromedial branch. Fibers attach on this aponeurosis posteriorly as far as the tip of the internal process of the mandible.

In $P$. gigas, all portions of this muscle are similar.

Discussion.-There are no major differences between Podilymbus podiceps and $P$. gigas in the bones, musculature, and ligaments of the skull. $P$. gigas has more powerfully constructed muscles in that fibers utilize all aponeurotic surfaces unoccupied and superficial in $P$. podiceps (such as Aponeuroses IX and III), and in their apparent relatively greater massiveness. Greater muscle force is also implied by better development of cranial crests and processes at points of fleshy and aponeurotic attachment. Podilymbus gigas has a bill that is deeper relative to its length than that of $P$. podiceps. Through the lever system of the upper jaw, a given muscle force is therefore translated into greater biting force in $P$. gigas because the ratio of the power arm (perpendicular from the frontonasal 

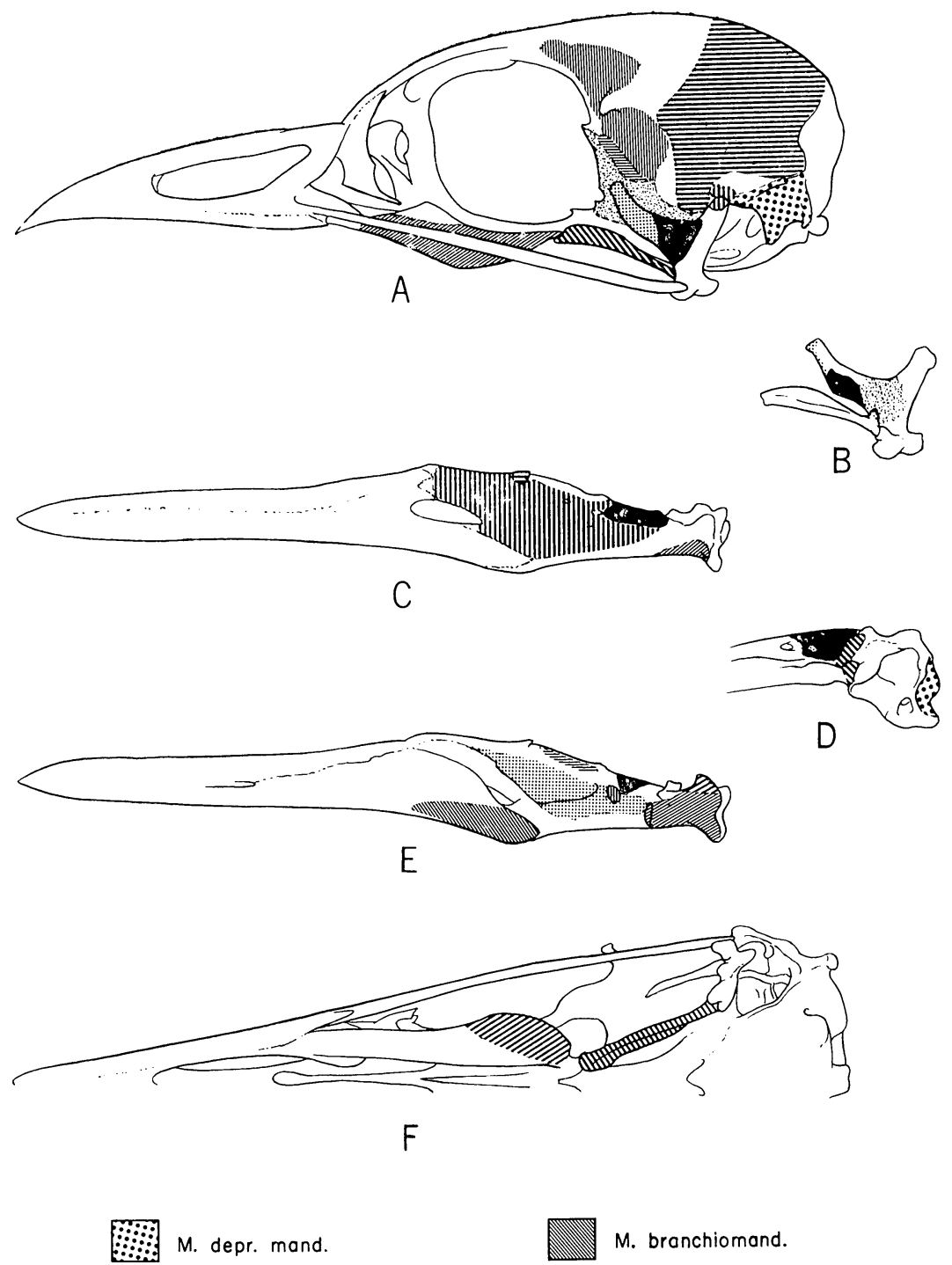

M. depr. mand.

M. branchiomand.

*. M. add. mand. post.

UIIIT) M. pteryg., ps. lat., dorsolat. br.

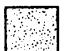

M. protr. quadr. pter.

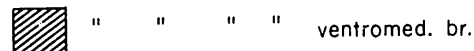

M. pseudotemp. prof.

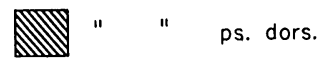

pseudotemp. superf., pt. I

M. add. mand. ext., pt. 2

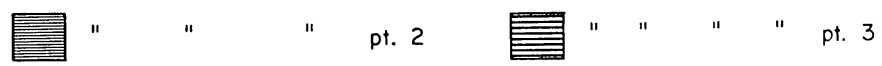

Fig. 6. Attachments of the jaw muscles of Podilymbus podiceps. Abbreviations: add.adductor, br.-branch, branchiomand.-branchiomandibularis, depr.-depressor, dors.dorsalis, dorsolat.-dorsolateral, ext.-externus, lat.-lateral, mand.-mandibulac, post.posterior, prof.-profundus, protr.-protractor, ps.-pars, pseudotemp.-pseudotemporalis, pt.-part, pter.-pterygoidei, pteryg.-pterygoidcus, quadr.-quadrati, superf.-superficialis, ventromed.-ventromedial. 
hinge to line of force of palatines) to the work arm (frontonasal hinge to bill tip) is greater in that species.

Differences between Podilymbus and Podiceps cristatus, however, are more striking. Comparison of our findings with the remarkably detailed description of $P$. cristatus presented by Bams (1956) indicates that Podilymbus lacks the prominent portion of $M$. adductor mandibulae covering $M$. pseudotemporalis superficialis and including Aponeuroses IV and $\mathrm{V}$ of Bams. By contrast, Podilymbus possesses a fleshy portion of M. pseudotemporalis superficialis (Part 2) not present in P. cristatus. In P. cristatus the postorbital process lies between the muscle masses of the pseudotemporalis superficialis and the adductor mandibulae, Part 3, and therefore close to the upper end of the crest of Aponeurosis X. In Podilymbus the postorbital process divides the pseudotemporalis superficialis muscle approximately in half and lies well anterior to the crest for Aponeurosis X. The strong Aponeurosis XI of the pseudotemporalis superficialis forks dorsally to supply the muscle portions on either side of the postorbital process.

Although Bams does not present an illustration of undissected superficial jaw musculature of $P$. cristalus, it is quite clear that Part 1 of $M$. adductor mandibulae is relatively less developed than in Podilymbus, and that the major aponeurosis of Part 2 (Ap. XII) lies lateral to that of Part 1 (Ap. IX), not medial to it as in Podilymbus.

In Podilymbus the strong aponeurosis (III) of $M$. adductor mandibulae, Part 3 broadens out dorsally into a sheet that parallels and follows the curved surface of the temporal fossa. Bams has shown that this aponeurosis in $P$. cristatus also follows the curve of the temporal fossa but is flattened in a plane perpendicular to the bony surface. The superficial appearance of this portion of the adductor mandibulae muscle in Podiceps cristatus and Podilymbus gigas is similar in that the fibers form a well-defined pennate muscle, but the orientation of the internal aponeuroses is quite different.

\section{MUSCLES OF THE HYOID APPARATUS (FIGS. 6, 7)}

For the hyoid bones and their associated musculature we have followed the terminology of Engels (1938). The detailed descriptions are of Podilymbus podiceps, followed by a brief comment for P. gigas.

M. serpihyoideus (Fig. 7) is a broad, flat muscle lying just under the skin in the throat region and immediately posterior to M. mylohyoideus. Anteriorly, its thin, fleshy origin is from the lateral edge of the posterior end of the mandible from the external process posteriorly along a ridge to Crest $\mathrm{T}$, then ventrally along this crest to the origin of M. stylohyoideus. 


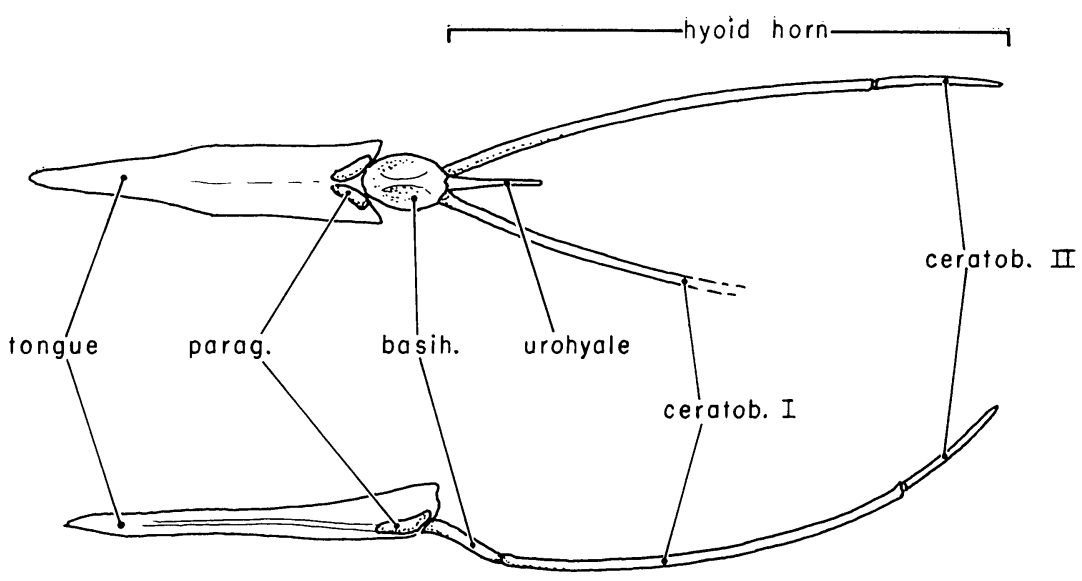

A

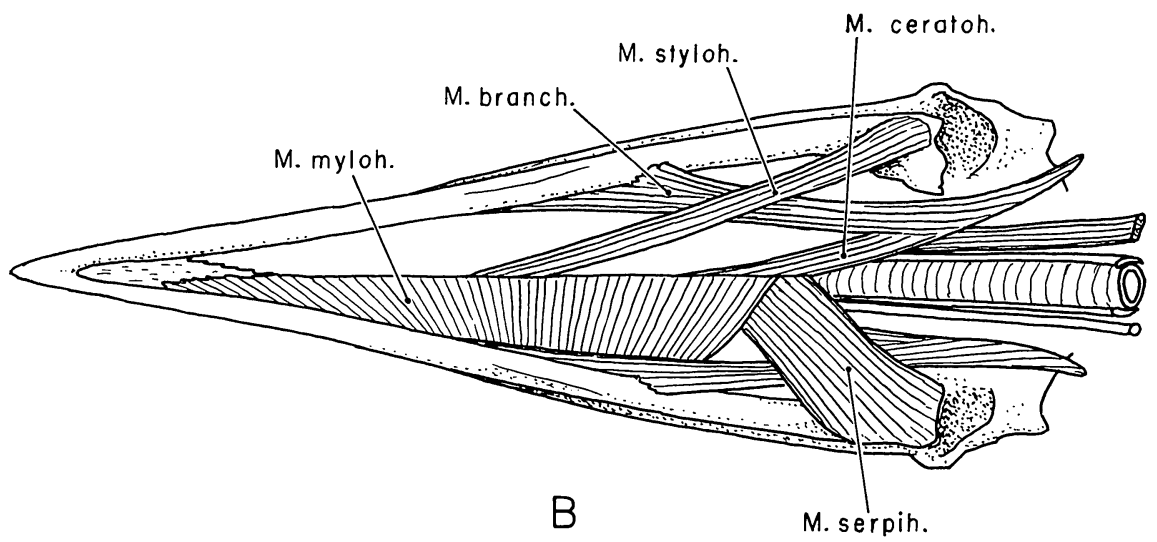

M. ceratog. ps. ant.

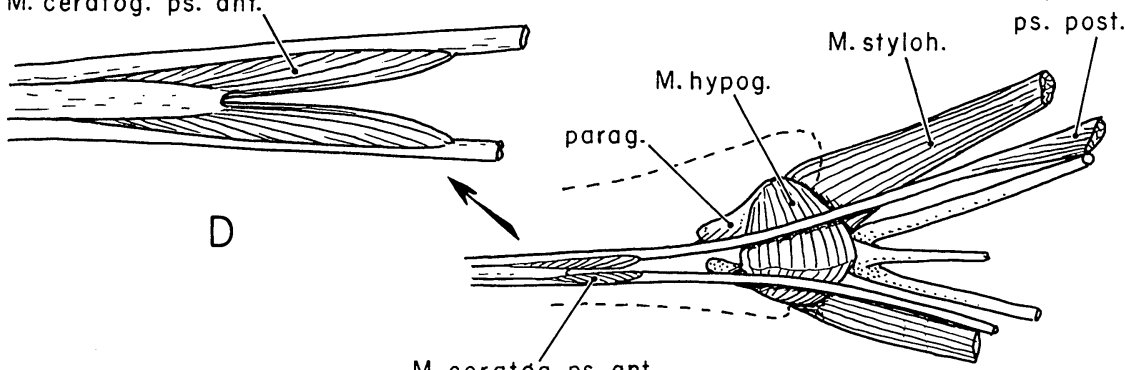

M. ceratog. ps. ant.

C

Fis. 7. Hyoid musculature of Podilymbus podiceps. A. Above, dorsal view of hyoid apparatus and tongue; below, lateral view. B. Ventral view of hyoid and throat musculature. M. serpihyoideus and $M$. mylohyoideus removed from left side. C. Detail of musculature at base of tongue (dashed line) in ventrolateral view. D. Enlargement of M. ceratoglossus anterior, ventral view. Abbreviations: ant.-anterior, basih.-basihyobranchiale, branch.-branchiomandibularis, ceratob.-ceratobranchiale, ceratog.-ceratoglossus, ceratoh.-ceratohyoideus, hypog.-hypoglossus posterior, M.-Musculus, myloh.-mylohyoideus, parag.-paraglossale, post.-posterior, ps.-pars, serpih.-serpihyoideus, styloh.stylohyoideus. 
The fibers run anteromedially and insert on a median raphe continuous with the raphe of $M$. mylohyoideus, where they are partially overlapped by $M$. mylohyoideus. Like that muscle, $M$. serpihyoideus has no connection with the hyoid apparatus and acts as a support for the throat. This muscle continues posteriorly as a thinner sheet forming a sling under the trachea. The fibers of this posterior portion originate from the skin of the neck and are tightly bound to it.

In $P$. gigas, the muscle is similar, but relatively thicker. The insertion is overlapped by $M$. mylohyoideus only slightly-somewhat less than in P. podiceps.

M. mylohyoideus (Fig. 7) is a superficial sheet of fibers formed by the paired muscles which run from the rami of the mandible to a common median raphe. The sheet extencls from near the angle of the jaw toward the symphysis. The muscle originates along a narrow line following the dorsal edge of the splenial bone and angling downward posteriorly to follow the dorsal edge of the prearticular bone. The insertion is on a median raphe running from near the symphysis to the posterior edge of the muscle. This muscle has no connection with the hyoid apparatus and acts as support for the floor of the mouth and the larynx.

In $P$. gigas this muscle is similar, but relatively thicker and the posterior portion is considerably thicker than the anterior portion. It overlaps $M$. serpihyoideus less than in $P$. podiceps.

M. ceratohyoideus (Fig. 7) is a very thin, strap-shaped muscle lying deep to $M$. serpihyoideus. Its fleshy origin is from the ventral portion of the posterior half to one-third of ceratobranchiale I. It runs anteromedially to insert on the median raphe common to $\mathrm{Mm}$. mylohyoideus and serpihyoideus where these muscles overlap.

In $P$. gigas this muscle is relatively thicker than in $P$. podiceps; the anterior half of its insertion lies dorsal to M. mylohyoideus and the posterior half dorsal to M. serpihyoideus.

M. stylohyoideus (Fig. 7) is a small, strap-shaped muscle lying deep to Mm. serpihyoideus and mylohyoideus. Its fleshy origin is from the posteroventral tip of the articular extending upward a short distance along Crest $\mathrm{T}$ and along most of Crest $\mathrm{R}$. The fibers run forward nearly parallel to the ramus. Most fibers cross the dorsal surface of the tendon of $M$. ceratoglossus posterior before inserting on the posterolateral edge of the basilhyobranchiale. Other fibers run along the ventral surface of the tendon and insert on tough connective tissue underlying $M$. hypoglossus posterior that continues forward on the floor of the tongue.

In $P$. gigas, the muscle is similar, but the origin on Crest $\mathrm{R}$ is restricted to the ventral portion of the crest. 
M. branchiomandibularis (Figs. 6, 7) is a strap-shaped muscle, somewhat thicker than the preceding ones. It envelops the posterior part of the hyoid horn, connecting this to the ramus of the lower jaw. The posterior fleshy attachment is to ceratobranchiale II, covering most of the surface of that bone except the ventrolateral face and the anterodorsal part of the bone, to which $M$. ceratoglossus, pars posterior attaches. Fibers also attach to all faces of the cartilaginous extension of ceratobranchiale II. The fibers attaching to the dorsolateral surface and some of those from the medial surface of ceratobranchiale II run almost directly to the attachment on the mandible; the remaining fibers from the medial surface make a half-turn around the ceratobranchiale to join the other fibers of the muscle. The main mass of the muscle runs nearly parallel to the ramus. The lateral portion is attached to the ventrolateral surface of the mandible just posterior to the angle of the jaw; the medial portion lies lateral to $M$. mylohyoideus and attaches on the posterior portion of the splenial bone from the angle of the jaw forward for approximately $10 \mathrm{~mm}$. (See Fig. 6.)

In $P$. gigas this muscle is similar.

M. ceratoglossus, pars posterior (Fig. 7) is a long, cylindrical muscle with a fleshy origin from the posterior one-half to two-thirds of the dorsal surface of ceratobranchiale I, swinging down onto the medial surface posteriorly, and from the anterodorsal part of ceratobranchiale II. A strong tendon forms on the dorsal surface of the muscle, receiving fibers for approximately one-half the length of the belly. The tendon continues forward along the dorsolateral surface of ceratobranchiale I, passing through a sheath formed by the fibers of $M$. stylohyoideus and beneath $M$. hypoglossus posterior, to insert on the ventral part of the cartilage of the tongue along almost its entire length. Between the bellies of pars anterior and pars posterior, the tendon is tightly bound to the paraglossale by stout connective tissue.

In $P$. gigas, the muscle is similar, but the origin is from the posterior one-half to one-third of ceratobranchiale I, as well as from the anterodorsal part of ceratobranchiale II. The belly is relatively shorter and thicker. The tendon and insertion are similar, but there is no close connection of the tendon with the paraglossale between the bellies of pars anterior and pars posterior.

Pars anterior of M. ceratoglossus (Fig. 7) consists of a few fibers originating from the tendon of pars posterior, just anterior to the paraglossale. These fibers run anteromedially onto their insertion on a flat tendon common to the right and left muscles. The tendon is tightly bound to the overlying tissues of the tongue and extends to its tip. 
In $P$. gigas, pars anterior is essentially as in $P$. podiceps, but it is better developed. Fibers spring from the dorsal and ventral surfaces of the tendon of pars posterior anterior to $M$. hypoglossus posterior. All fibers run anteromedially, forming a cylindrical belly in the floor of the tongue. They attach along the dorsal surface of a tendinous sheet forming the floor of the tongue.

M. hypoglossus posterior (Fig. 7) is a broad, rather thick, transverse band of muscle connecting the two paraglossales and lying ventral to the basihyobranchiale. It originates on the whole posterior edge of the paraglossale, the fibers spreading out to form a band approximately $4 \mathrm{~mm}$. wide. The fibers from each side meet in the midline to form what is functionally a single muscle. A well defined median raphe is present; connective tissue of the raphe extends forward along the anterior cartilage of the basihyobranchiale.

In $P$. gigas, this muscle is similar.

$M$. thyreohyoideus is a conspicuous strap-like longitudinal muscle running between the larynx and the basihyobranchiale. Its fleshy origin is from a large area in the anterodorsal depression of the basihyobranchiale. The fibers run posteriorly, filling this depression, and insert along a narrow line on the lateral and posterodorsal surface of the cricoid cartilage. The lateralmost fibers continue posteriorly further than the others to insert on the roof of the larynx posterolaterally.

In $P$. gigas, this muscle is similar.

M. geniohyoideus-genioglossus and M. tracheohyoideus are absent.

\section{THE CERVICAL VERTEBRAE (FIGS. 8, 9, 10)}

Each cervical vertebra is different, variations in its structure being correlated with the functional properties of the neck, as admirably explained by Boas (1929). Vertebrae may be grouped into three general types, corresponding with three regions of the neck (see Fig. 8). Our treatment here follows the concept of regions defined by the types of mobility of their vertebrae (Zusi, 1962: 68-71), but we prefer to call these regions "sections," rather than "segments," the term which Zusi employed. The latter term might bring to mind a segmented muscle or an individual vertebra or muscle of a series; the former connotes a group of units (vertebrae) rather than the units themselves.

The first section (I) in Podilymbus consists of the anterior 8 vertebrae and is capable of downward flexion but only slight upward flexion from a straightened position. The second section (II), vertebrae 9 through 15, can be flexed upward but not downward, whereas the third section (III), vertebrae 16 through 19, can be flexed downward and also slightly 


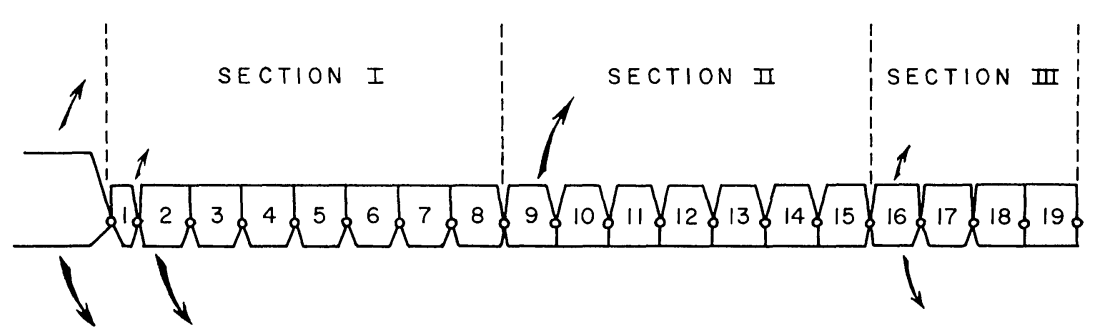

FIG. 8. Diagram of cervical vertebrae and functional sections of the neck in Podilymbus. Vertebrae numbered from front to back. Potential for upward or downward movement of sections indicated by arrows and shapes of vertebrae.

upward. All sections are capable of some lateral flexion. The head can be flexed downward and upward beyond a line continuous with the straightened position of section I.

Section I.-The atlas and axis are specialized vertebrae bridging the gap between the functional requirements of the neck and those of the head. The atlas and skull articulate in a ball-and-socket joint which allows maximum freedom of movement of the head. The atlas is closely bound to the axis, but some transverse rotation is possible between them. The axis is modified to receive the insertion of several major neck muscles and to provide points of origin for special muscles moving the head. The remainder of the first section (vertebrae 3 through 8 ) is confined to downward flexion by facets of the pre- and postzygapophyses that face anterodorsally and posteroventrally, respectively, by anapophyses that protrude backward beyond the postzygapophyses, and by a posterior border of the neural arch that lies at the same level as the posterior border of the facets of the postzygapophyses. This border forms a stop against the next posterior neural arch and limits upward flexion. Downward flexion is facilitated by the anteroventral orientation of the anterior articular facet of the centrum, by the presence of an anteroventral pit on the centrum that receives the posterior border of the centrum anterior to it, and by a sufficient distance between the sublateral processes of each vertebra and the postlateral processes of the next anterior vertebra to prevent these processes from afting as stops.

In the first section, a hypapophysis is well developed on vertebrae 2 and 3 , ribs are present on the transverse processes, the neural spines are fairly well developed, and a supraarticular groove is present medial to the anapophysis.

Section II.-These vertebrae are modified for upward flexion by the facets of the prezygapophyses facing dorsally, by the posterior and anterior borders of the neural arch being cut in to allow intermeshing during 


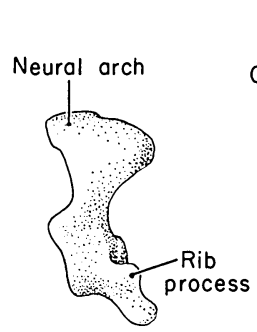

1

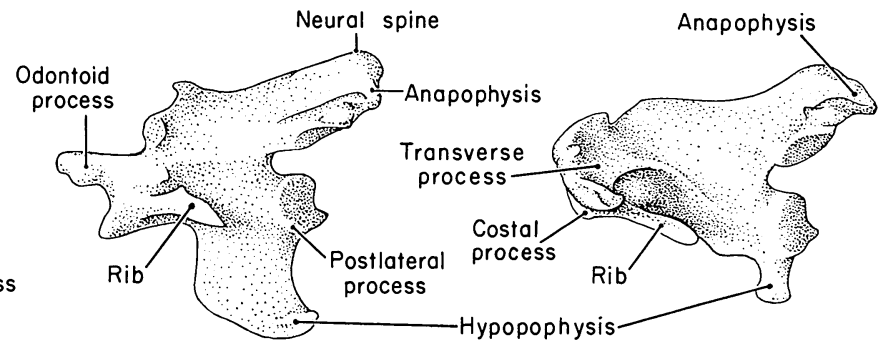

2

3
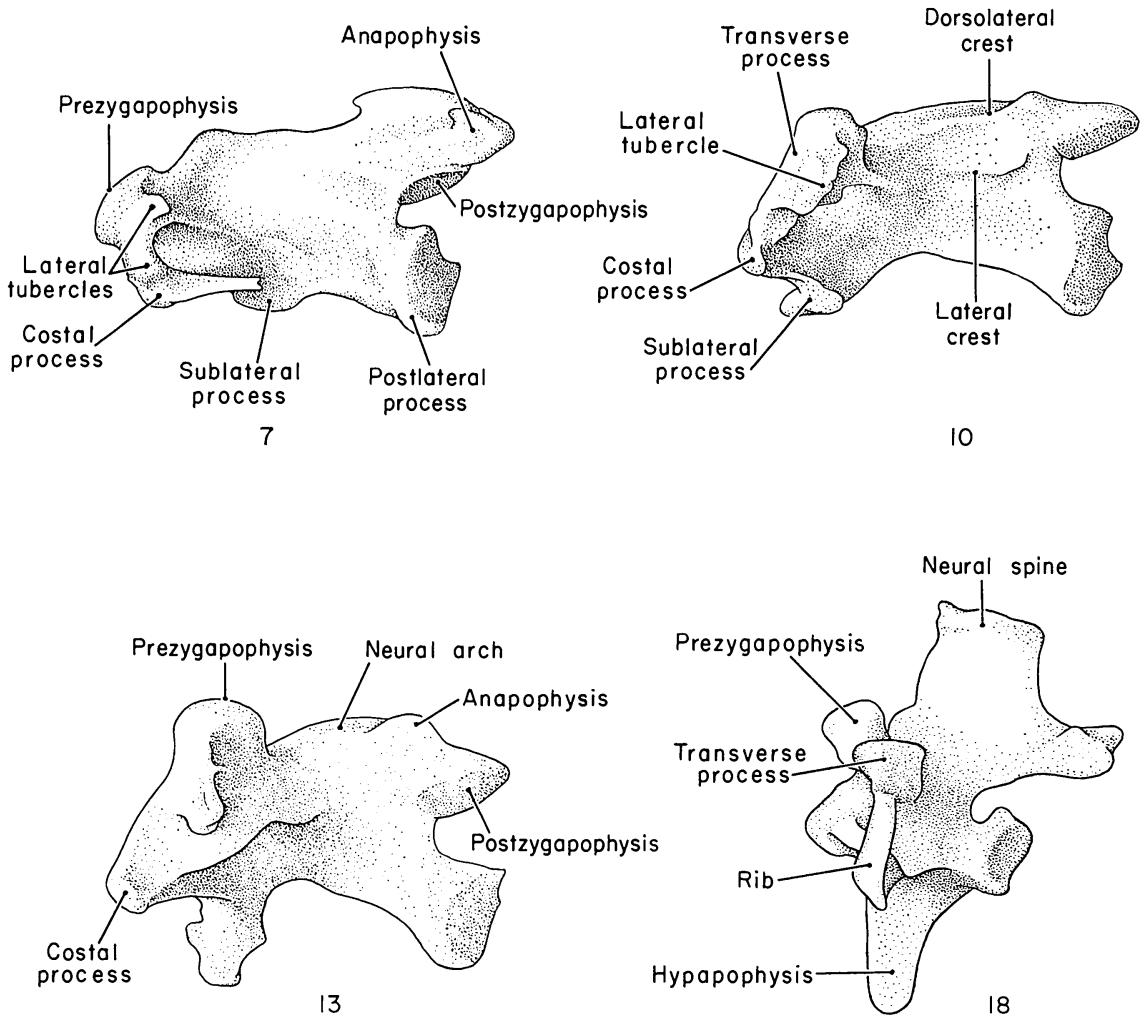

FIG. 9. Topography of cervical vertebrae of Podilymbus podiceps, lateral view. Vertebrae numbered starting with atlas. 

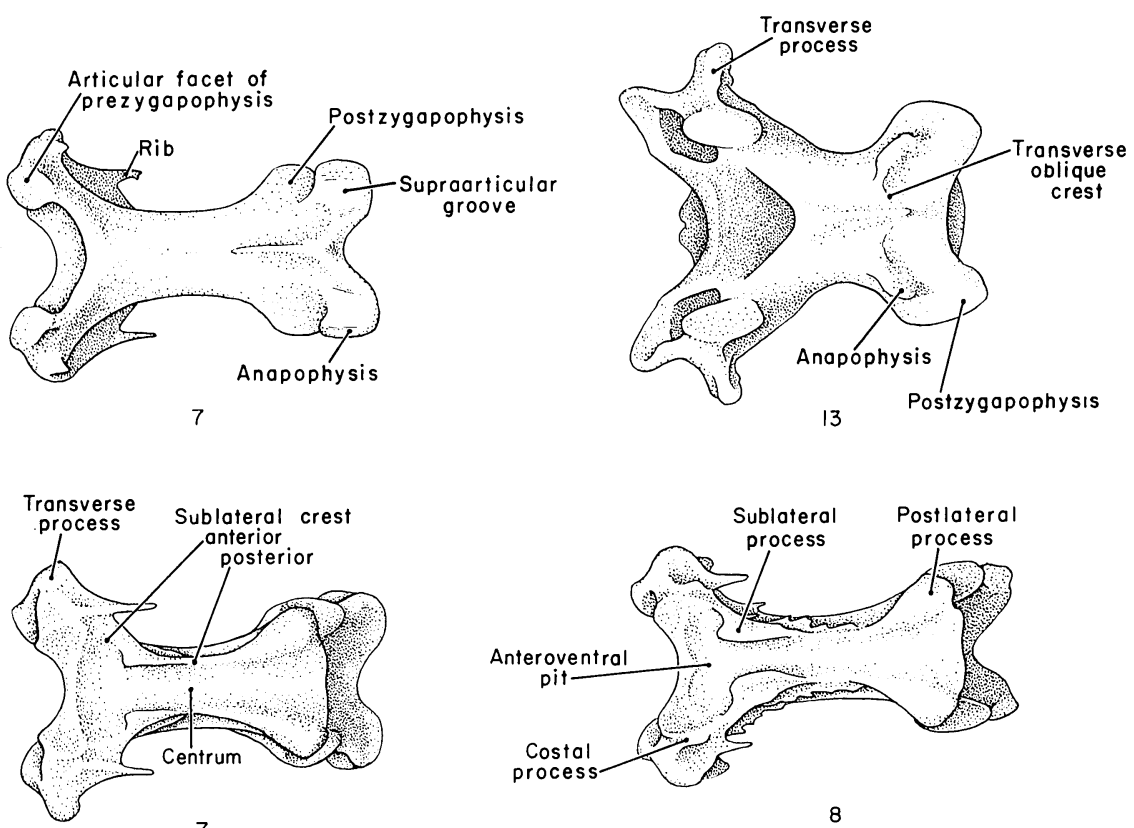

7

8

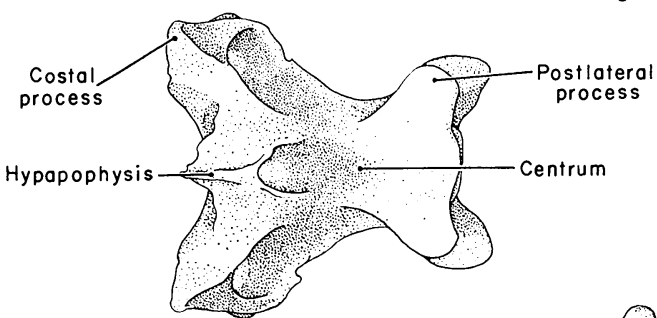

15

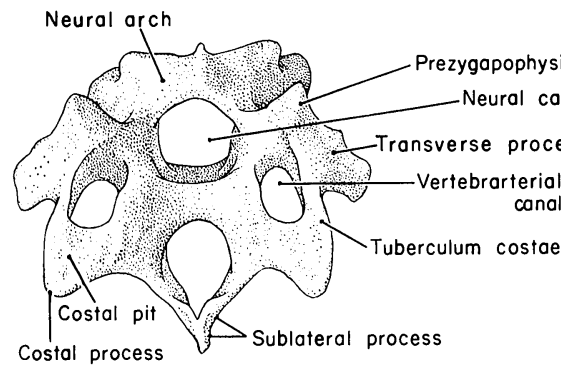

13

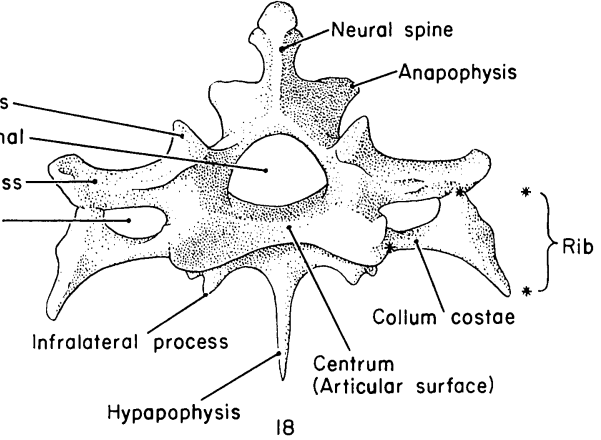

Fig. 10. Topography of cervical vertebrae of Podilymbus podiceps. Vertebrae numbered starting with atlas. Top figures $(7,13)$ in dorsal view; middle figures $(7,8,15)$ in ventral view; bottom figures $(13,18)$ in anterior view, 
flexion, by the anterior facet of the centrum facing anterodorsally, and by the sublateral processes having moved forward and the anterior sublateral crests having become more transverse so that the latter abut against the postlateral processes, thus preventing downward flexion.

Characteristics of vertebrae of the second section are the forward position of the anapophyses, the prominence of the lateral and dorsolateral crests, the absence of ribs, the absence of neural spines, the formation of the hypapophyses posteriorly through the fusion of the sublateral processes, the well developed costal processes, and the flattened, horizontal region between the transverse-oblique crest and the posterior edge of the neural arch.

Section III.-Vertebrae of this section are characterized by the concave, vertical wall between the transverse-oblique crest and the posterior edge of the centrum, by the presence of a neural spine (small in 16 and 17), well developed hypapophyses, and by the presence of lateral tubercles on the tips of the winglike transverse processes.

The cervical vertebrae of Podilymbus podiceps and $P$. gigas are similar in most respects, but the processes, crests, and ridges are relatively more strongly developed in gigas.

\section{THE NEGK MUSCLES (FIGS. 11-19)}

The most comprehensive treatment of avian neck musculature is that of Boas (1929). Although he dissected Podiceps cristatus as part of a survey of many orders of birds, he described only $M$. longus colli ventralis and Mm. splenii of Podiceps. Our interpretation and terminology of the neck muscles follow Boas with the following exceptions: we include $\mathrm{Mm}$. inclusi with $M m$. intertransversarii and $M m$. interspinales with $M m$. intercristales because of the difficulty of separating these muscles in Podilymbus; we treat $M$. splenius capitis and $M$. splenius colli as different muscles; in complex serially-arranged muscles we regard the functional units to be those fibers inserting on a given vertebra rather than those originating from a vertebra.

For brevity we often refer to a particular vertebra simply by its number. Vertebrae are numbered consecutively, starting with the atlas.

M. complexus (Figs. 11, 12, 19) is a broad, flat muscle, covered in part anteriorly by $M$. adductor mandibulae, pt. 3. It lies mostly superficially on the anterodorsal part of the neck and originates by three slips-a weak one from the lateral tubercle ${ }^{1}$ of 3 and stronger ones from the lateral

1 The lateral tubercle is a swelling on the eind of the transverse process on all cervical vertebrae except the atlas and axis. It lics between the prezygapophyses and the costal process and may be single or double (dorsal and ventral). 


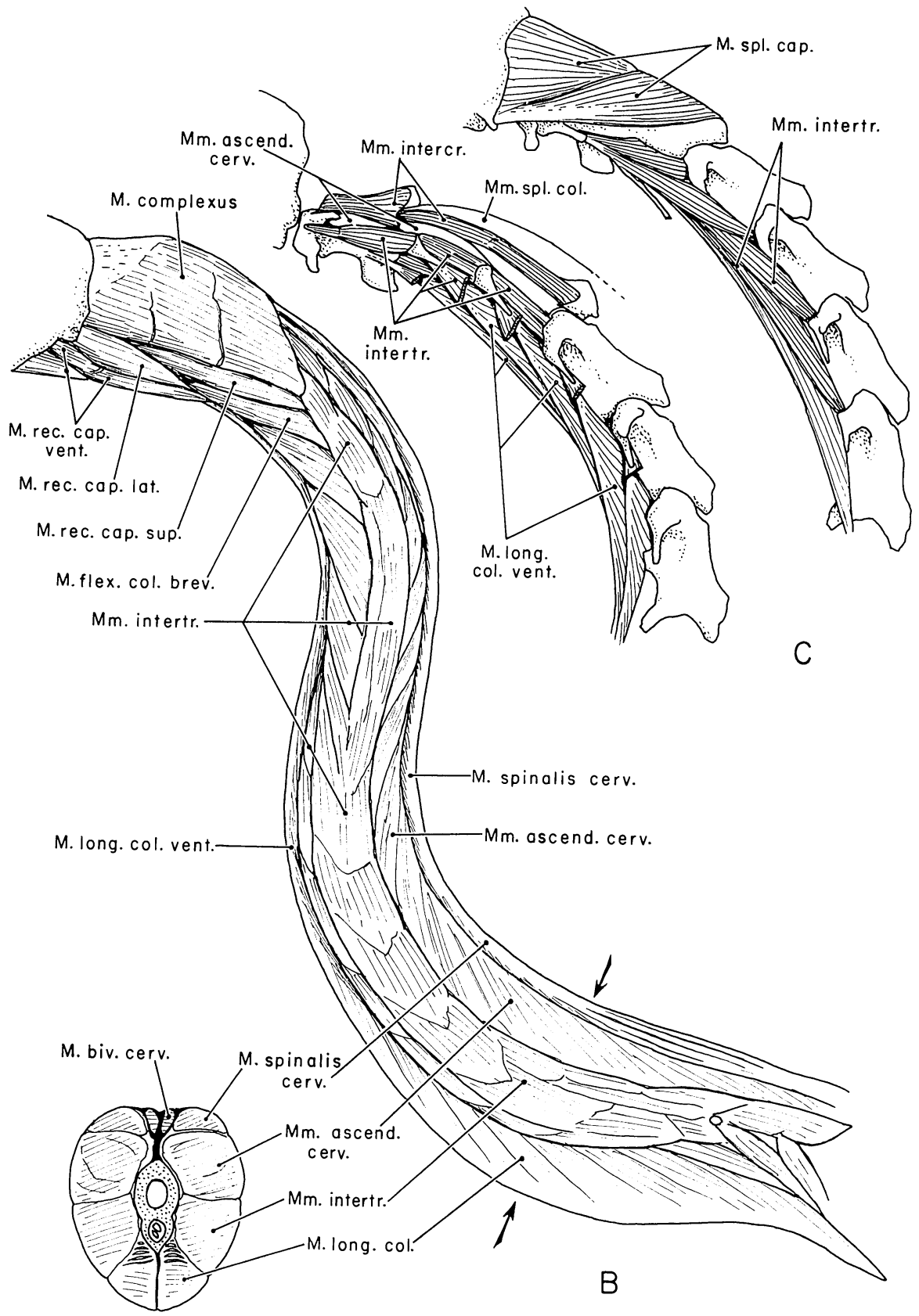

A

Fig. 11. Cervical muscles of Podilymbus. A. Cross section through vertebra 15, P. gigas. B. Superficial neck muscles from left side, P. gigas. Arrows indicate plane of cross-section (A) . C. Anterior deep neck muscles of P. podiceps. Mm. splenii colli and Mm. ascendentes cervicis unshaded for clarity. Abbreviations: ascend.-ascendentes, biv.-biventer, brev.brevis, cap.-capitis, cerv.-cervicis, col.-colli, flex.-flexor, intercr.-intercristales, intertr.intertransversarii, lat.-lateralis, long.--longus, M.-Musculus, Mm.-Musculi, rec.-rectus, spl,-splenii, sup-superior, vent,-ventralis, 
tubercles and short aponeuroses running forward from the tubercles of 4 and 5. Along its posteromedial edge it arisss from a thin aponeurotic sheet that covers the other superficial neck muscles and that is tightly bound to the anapophysis of 4 . The slip from 5 is superficial whereas the slips from 4 and 3 lie progressively deeper and combine anteriorly with the other slip to form a single belly.

The muscle is partially divided into three segments by two transverseoblique tendinous intersections as shown in Fig. 11. All fibers of the third (i.e. posterior) segment terminate on the second tendinous intersection; fibers originating from the lateral half of the second intersection and the
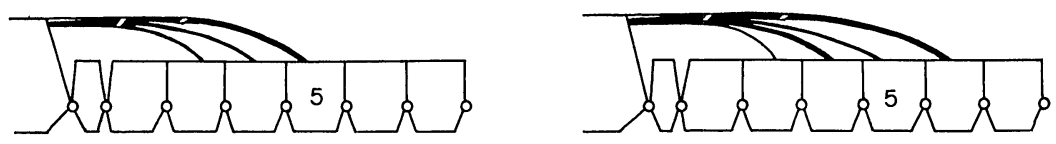

Fig. 12. Diagram of M. complexus. Left, Podilymbus podiceps. Right, P. gigas. Tendinous intersections shown as cross bars in muscle.

slips from 3 and 4 terminate anteriorly on the incomplete first intersection; fibers from the medial half of the second intersection and all those from the first intersection run forward to their insertion on the ventral surface of a tough aponeurosis that inserts on the skull along the occipital crest, Crest $\mathrm{C}$, and the dorsal portion of Crest A. The dorsal surface of this aponeurosis serves as an accessory area of origin of M. adductor mandibulae.

In $P$. gigas the muscle has a similar structure but the three main slips originate from 4,5 and 6 , and a few fibers arise from the transverse process of 3. Slips from 4 and 5 terminate on the incomplete first tendinous intersection; the slip from 6 and all fibers medial to it attach on the complete second intersection.

M. biventer cervicis (Figs. 11, 14) is a long, slender muscle extending the full length of the neck just lateral to the mid-dorsal line. It has two bellies connected by a slender tendon. The muscle runs through an aponeurotic sheath which is bound to the medial surface of a stronger sheath enclosing $M$. spinalis cervicis (Fig. 11A). The posterior belly is closely associated with $M$. spinalis cervicis and the anterior belly with $M$. complexus.

The muscle originates by a long slender tendon having as its strongest attachment the anterodorsal tip of the neural spine of 19. This tendon is covered and tightly bound by the tough aponeurosis of origin of $M$. spinalis cervicis. The tendon of origin of the biventer lies along the medial edge of this aponeurosis and adjacent to the tendon of the opposite biventer 
cervicis; the biventer's tendon is loosely bound to the dorsal edge of the neural spine of 18. Anterior to this the tendon loses its association with the aponeurosis of origin of the spinalis cervicis and.runs along the medial edge of the main fleshy slip of the spinalis for a short distance. The tendon gives way to a long slender belly that equals in length the adjacent anterior slip of $M$. spinalis cervicis. The belly in turn terminates on a tendon running near the dorsal midline of the neck as far as vertebra 3 where it gives rise to a second slender belly running deep to $M$. complexus.

The anterior belly inserts by a short tendon that fuses with the ventral surface of the aponeurosis of insertion of $M$. complexus and attaches on the occipital crest near its midpoint.

This muscle is similar in $P$. gigas.

$M$. rectus capitis lateralis (Figs. 11, 19) is a thick strap-like muscle lying between $M$. rectus capitis ventralis and $M$. rectus capitis superior. Its origin is from the lateral surfaces of the hypapophyses of 2 and 3 and from short aponeuroses attaching on these hypapophyses.

The fibers insert by an aponeurosis on the ventral and lateral surfaces of the belly. This aponeurosis attaches on the opisthotic process and Crest B lateral to the attachment of the aponeurosis of $M$. splenius capitis.

The muscle is similar in P. gigas.

$M$. rectus capitis superior (Figs. 11, 13, 19) is a partly superficial muscle lying ventral to $M$. complexus and partly deep to $M$. rectus capitis lateralis.
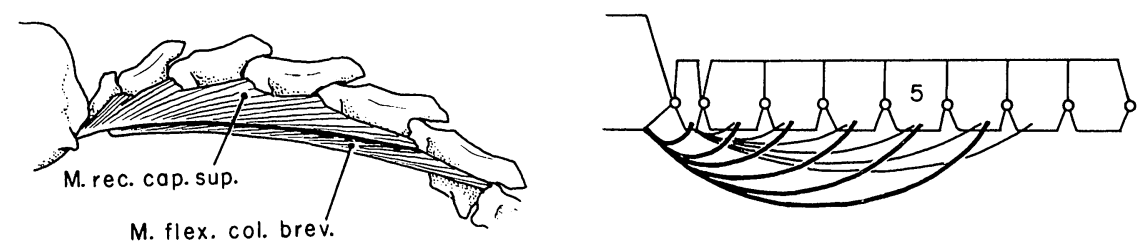

FIG. 13. M. rectus capitis superior and $M$. flexor colli brevis of Podilymbus podiceps. Left, drawn from dissection. Right, diagram of slips; rectus capitis superior represented by heavier lines.

The origin is from short aponeurotic sheets on the costal processes of 6,5 , 4 , and 3. The aponeurosis from 4 is the most extensive. In each case these attachments are adjacent and anterior to those of $M$. complexus. These main origins are connected by thin lines of short aponeurotic fibers that spring from the ventrolateral edges of the intertransversarii muscles. Fibers also originate from an aponeurosis extending forward from the dorsolateral edge of the vertebrarterial canal of 3 (lateral to the aponeurosis of $M$. flexor colli brevis), from the anterolateral surface of the neural arch 
of the axis, and from the lateral surface of the atlas. The main insertion is by a superficial aponeurosis lying along the ventrolateral surface of the belly. The aponeurosis becomes a rather stout tendon before inserting on a prominent knob of the basitemporal plate, anterolateral to the occipital condyle. The ventral fibers of the muscle have a fleshy insertion on the basitemporal plate medial to the main tendon and just anterior to the occipital condyle; those arising from the atlas and axis insert on the skull just dorsal to the main tendon.

In $P$. gigas this muscle is similar.

$M$. rectus capitis ventralis (Figs. 11, 19) is a superficial muscle of the anteroventral portion of the neck. It originates from the sides of median aponeuroses extending anteroventrally from the hypapophyses of 1, 2, and 3 , and from an aponeurosis joining hypapophyses 1 and 2. Origin of more posterior slips is from the postlateral process of 3 and partly tendinous from the posterior sublateral crest of 4 and the sublateral processes of 5 and 6; also from the tough sheath of fascia enclosing the carotid arteries. Additional area of origin is provided by the aponeuroses extending forward from the sublateral processes of 5 and 6 .

Insertion is on the entire ventral surface of the basitemporal plate from the transverse crest to the attachment of $M$. rectus capitis superior. The attachment is primarily fleshy, but fibers also insert on an aponeurosis attaching on a roughened surface directly medial to the foramen for the internal carotid artery. Some fibers attach on the bone surrounding this foramen.

This muscle can be divided into anteromedial and posterolateral portions. The posterior limit of origin for the anteromedial part is vertebra 3 (hypapophysis) whereas the posterolateral part originates on 3, 4, 5, and 6 . The two bellies are partially separated by the carotid artery, and they insert differently, the posterolateral part occupying the more lateral, tendinous insertion. The posterolateral portion is divided into two segments by a tendinous intersection crossing the belly transversely from its lateral edge (at the level of the posterior border of hypapophysis 2) and curving anteriorly to the medial edge of the muscle (at the anterior border of hypapophysis 2).

The muscle is similar in $P$. gigas.

M. splenius capitis (Figs. 11, 19) is a stout muscle lying deep to the complexus and biventer cervicis. It consists of two portions originating from vertebrae 2 and 3 respectively.

The anterior portion originates from the side of a median aponeurosis extending forward from the tip of the neural spine of 2 and from an aponeurosis extending anterolaterally from the spine. These aponeuroses 
are embedded in the belly of the muscle. The muscle fans out from its origin to a broad insertion along a thin line on the posterior wall of the skull immediately deep to the insertions of $M$. biventer cervicis and $M$. complexus, and extending lateral to the complexus onto the posterior surface of the opisthotic process.

The posterior portion originates from the sides of a median aponeurosis extending from the neural spine of 2 to the mid-line of neural arch 3 . From this origin the fibers converge onto the medial surface of a strong aponeurosis attaching on the opisthotic process, medial to the attachment of $M$. rectus capitis lateralis. The fibers of the two parts of the muscle are not clearly separable where they come together, but the two portions are recognizable in that the posterior portion resembles a fan with its base at the insertion and the anterior portion a fan with its base at the origin.

The muscle is similar in $P$. gigas.

Mm. splenii colli (Figs. 11, 14, 19) consist of a series of bellies running from the neural arches of vertebrae of the first and second neck sections to the long tendon of insertion of $M$. spinalis cervicis. The posteriormost slip is slender and arises from the neural arch of 14 near the mid-line. Slips arising from 13, 12, 11, 10, and 9 are relatively stronger and arise from the entire medial part of the roof of the neural arch between the vertebral mid-line and the belly of $\mathrm{Mm}$. intercristales. The slip arising from vertebra 8 is intermediate in size between the larger posterior slips and those arising from 7 through 3 . The origins of slips of the first section are close to the mid-line and the more anterior slips are restricted to the posterior part of the neural arch along the neural spine where they arise in part from short aponeuroses.

All slips insert on the strong tendon by which the first slip of $M$. spinalis cervicis inserts on the anapophysis of the axis; in addition the slip originating from 3 has a fleshy insertion on the anapophysis around the tendon. The two posterior slips of $\mathrm{Mm}$. splenii colli insert on the ventral surface of the tendon; the other slips insert in series on its medial and dorsal surfaces.

Another short belly lying deep to M. splenius capitis and medial to the anterior part of $\mathrm{Mm}$. splenii colli represents $M$. splenius anticus of Boas (1929: 165). The spindle-shaped belly originates from the posterodorsal mid-line of vertebra 3 and runs forward in close association with $\mathrm{Mm}$. intercristales, inserting by a narrow tendon that blends with the broader aponeurosis of insertion of that muscle attaching on the posterior edge of the neural arch of the atlas.

Mm. splenii colli and anticus are similar in P. gigas.

M. spinalis cervicis (Figs. 11, 14) is a large, complex muscle consisting 
of ten slips running from the neural spines of the thoracic and posterior cervical vertebrae to the anapophyses of the axis and of vertebrae 11 through 19. The fleshy part of the muscle lies posteriorly over section 3 and part of section 2; it reaches the axis by a long tendon that also serves as the tendon of insertion of $M$. splenius colli. Anteriorly the slips are readily separable but posteriorly they form an almost solid muscle mass. The posterior slips are difficult to separate from those of M. spinalis thoracis and of Mm.ascendentes cervicis.

The anterior six slips of this muscle originate from a broad aponeurosis extending anteriorly and laterally from its attachment on the dorsal ridges of the neural spines of vertebrae 18, 19, and 20. The first slip (running to

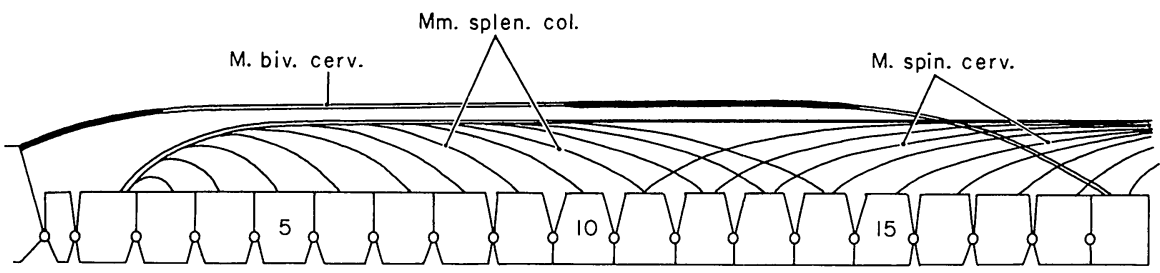

Fic. 14. Diagram of $M$. biventer cervicis, Mm. splenii colli, and $M$. spinalis cervicis in Podilymbus. All slips running to left and downward belong to spinalis; slips running to left and upward are splenii. Splenii and first slip of spinalis share common tendon to vertebra 2 .

the axis) originates from the anteromedial edge of the aponeurosis near the neural spine of 18 . The second slip (to vertebra 11) originates posterolateral to the first slip; the third, fourth, fifth and sixth slips originate in succession by attachments running diagonally across the ventral surface of the aponeurosis. (The narrow tendon of $M$. biventer cervicis runs near the clorsal mid-line deep to the medial edge of the large aponeurosis of this muscle.) Fleshy fibers of the seventh slip spring from a narrow aponeurosis near the tip of neural spine 21. The aponeurosis runs back along the spines to vertebra 24. This slip lies adjacent to the lateral edge of the larger aponeurotic sheet and farther forward the slip lies deep to those originating from that sheet. The eighth slip lies lateral and adjacent to the seventh, originating from an ossified tendon running anteriorly from the anterior spines of the synascrum. The ninth and tenth slips are small and lie deep to the others, originating from the same ossified tendon and from the transverse processes of thoracic vertebrae.

The largest and most anterior slip inserts at the level of vertebra 10 on the posterodorsal surface of a long tendon that continues forward to its attachment on the anapophysis of 2. The second slip, deep to the first, 
inserts on the medial surface of the aponeurosis of $M m$. ascendentes cervicis attaching on the anapophysis of 11. Slips 3 through 10 insert in similar fashion on anapophyses 12 through 19 respectively. The posterior aponeuroses of insertion of $\mathrm{Mm}$. ascendentes are relatively longer and more slender than the anterior ones and the slips attach on the aponeuroses well behind the anapophyses on which they ultimately insert (for example, the 9 th slip to vertebra 18 attaches on its aponeurosis at the level of vertebra 21). The muscles lying in the angle between the neural spines and transverse processes of the thoracic vertebrae are compacted into a multipennate muscle mass. $M$. spinalis thoracis constitutes a series of pennate bellies inserting on slender tendons (some ossified) attaching on the postero-dorsal tips of the neural spines of the thoracic vertebrae and of cervicals 19 and 18 , and on 17 between the anapophysis and neural spine. These bellies originate from ossified tendons running forward from the synsacrum and from the lateral surfaces of the thoracic neural spines. $M$. spinalis cervicis originates in part from the same ossified tendons as thoracis, but primarily by the aponeuroses already described running forward from the tips of the neural spines above the spinalis thoracis. Also arising in part from the lateral surfaces of the same ossified tendons are $\mathrm{Mm}$. ascendentes cervicis which share the tendons of insertion of $M$. spinalis cervicis and lie lateral to that muscle.

This muscle complex is similar in $P$. gigas.

$M m$. dorsales pygmaei are apparently either vestigial or rudimentary in Podilymbus. In a specimen of $P$. podiceps only one belly was found (its lateral counterpart was probably overlooked). The muscle is mostly fleshy and slender, arising by a short thin tendon from the neural spine (double) of 16 and extending forward to an aponeurotic attachment on the neural spine (very small) of 14 just posterior to the last slip of $M m$. splenii colli. The muscle lies along the medial surface of $M m$. intercristales. We found no trace of this muscle in one specimen.

One specimen of $P$. gigas had a single belly from 16 to 14 as in $P$. podiceps. $M m$. intercristales (Figs. 11, 19) form a series of seventeen dorsal muscles running from the postzyagapophysis and neural arch of one vertebra to the postzygapophysis of the adjacent anterior vertebra. The posterior belly of the series runs from vertebra 20 to 19 while the anterior belly runs from 2 to 1 . The medial portions of the bellies running between the neural spines of 2-3, 3-4, 17-18, 18-19, 19-20 probably correspond to $M \mathrm{~m}$. interspinales of Boas (1929). Anteriorly, bellies of $M \mathrm{~m}$. intercristales are closely associated with the more lateral $\mathrm{Mm}$. ascendentes cervicis and medially with the slips of $\mathrm{Mm}$. splenii colli.

The posterior two bellies are relatively small, but others of the third 
section are larger, covering the entire dorsal surface of the neural arch except its mid-line. They originate on the dorsal surfaces of the postzygapophyses and the adjacent posterodorsal part of the neural arch, and run forward to insert on the depression bounded by the anapophysis, transverse-oblique crest, and posterior edge of the neural arch. Fibers also insert on a tough sheet of fibrous connective tissue extending back from the posterior edge of the roof of the neural arch to the neural arch of the next posterior vertebra. The belly connecting 14 and 13 and the more anterior bellies of the second section are smaller than those just described and the depression in which they insert is shallower. Their origin is from the anterior surface of the anapophysis and the lateral part of the transverse-oblique crest. The dorsomedial surface of the neural arch is occupied by the splenii colli muscles, displacing the medial portion of the intercristales. Bellies of the first neck section are the largest and most powerful of the series. Beginning with the belly connecting 9 and 8 , the muscle again occupies most of the dorsal surface of the neural arch (the splenii colli in the first section are much reduced and attach near the mid-line). The dorsal surface of the postzygapophysis, occupied by this muscle in vertebra 8 , serves to support the tendon of insertion common to the spinalis and splenii muscles in vertebrae 7 through 3 by means of the supraarticular groove. The bellies of the intercristales of 7 through 3 insert on the posterior face of the neural arch, and on the postzygapophysis between the articular facet and the supraarticular groove. Fibers also insert on strong aponeuroses-a long lateral one from the anapophysis and a shorter one from the posterodorsal edge of the neural arch. The lateral portion of the anterior bellies is strongly developed and it is visible superficially between the ascendentes cervicis and the spenii colli muscles. The anterior bellies of the first section arise from the entire dorsolateral surface of the neural arch; some fibers of these bellies insert on the tendons of insertion of $M m$. ascendentes cervicis. The first belly of the series inserts by an aponeurotic sheet on the posterior rim of the neural arch of the atlas in common with the narrow tendon of insertion of M. splenius anticus.

$M m$. intercristales are similar in P. gigas.

Mm. ascendentes cervicis (Figs. 11, 15, 19) are a series of overlapping bellies lying along the dorsolateral part of the neck from the thorax to the atlas. Each functional unit might best be considered as all of the slips inserting on a given vertebra, although Boas (1929) described the muscles in terms of all slips originating from a given vertebra. The insertion of each muscle is on the anapophysis and an aponeurosis extending back from the anapophysis. This aponeurosis is shared by other muscles: in the 
first section its anteromedial surface receives fibers from $M m$. intercristales; in the third section it receives fibers from $M$. spinalis cervicis. Origin is from the dorsomedial surface of a broad aponeurosis extending lorward from the dorsal lateral tubercle of the transverse process and from the dorsal surfaces of the winglike transverse processes of 17 through 24. Each vertebra of the first section receives a slip from the second and third vertebrae posterior. Vertebra 8 receives slips from the second, third, and fourth vertebrae posterior while most vertebrae of the second section
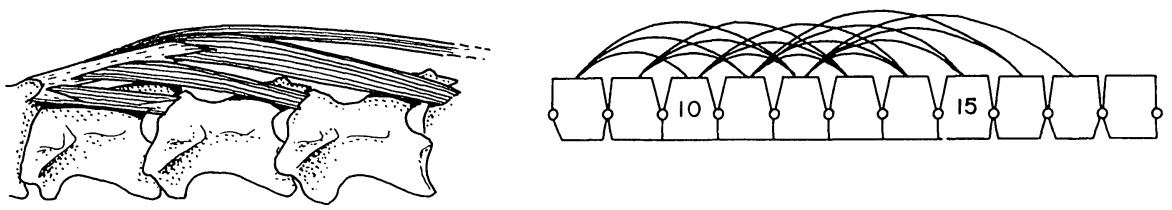

FIg. 15. Mm. ascendentes cervicis in Podilymbus. Left, semidiagrammatic drawing of a single muscle. Right, diagram of slips of five muscles.

receive an additional slip from the fifth vertebra. (See Fig. 15 for arrangement of slips.) The strongest belly in each group of slips inserting on a given vertebra is generally that which originates from the third vertebra posterior to the insertion.

From vertebra 17 and posteriorly, the origin is from the dorsal surface of the transverse process between the lateral tubercle and the articular facet of the prezygapophysis, and from the dorsal surface of an extensive horizontal aponeurosis extending forward from the edge of the transverse process. Vertebra 17 is supplied by fibers from 24 through 19 . Vertebra 18 receives from 24 through 20, and 19 receives from 23, 22 and 21; fibers originating from the lateral surfaces of the ossified tendons from the synsacrum shared by $M$. spinalis thoracis also insert on 18 and 19.

This muscle series is similar in P. gigas.

M. flexor colli brevis (Figs. 11, 13, 19) is a flat, fan-shaped muscle lying on the lateral surface of the neck (first section), deep to $M$. rectus capitis superior and lateral to the ventral slips of $M \mathrm{~m}$. intertransversarii. It originates from the lateral surfaces of the aponeuroses of origin of $\mathrm{Mm}$. intertransversarii that attach on the ventral tips of the costal processes of 7, 6 and 5 ; from the ventral tip of the costal process of 4 , from the lateral surface of the rib and costal processes of 3 and 2. Fibers also spring from an aponeurotic line between the costal processes of 5 and 4 , and from the lateral surfaces of aponeuroses which extend forward from the anterior edges of the transverse processes. 
The fibers insert on a superficial aponeurosis that becomes a stout tendon before attaching on the rib process of the atlas and the posteroventral border of the centrum.

The muscle is similar in $P$. gigas.

Mm. intertraversarii (Figs. 11, 16, 17, 19) constitute the principal lateral musculature of the neck and consist basically of a series of multipennate bellies connecting the transverse processes of adjacent vertebrae. They share certain aponeuroses below with $M$. longus colli ventralis, and above with $M m$. ascendentes cervicis. On the second section the bellies are intimately associated with fibers and aponeuroses of $\mathrm{Mm}$. inclusi, which are therefore described together with this muscle.

The structure of the complex bellies differs markedly between the first and second sections, and in detail in any two successive bellies. Throughout the muscles the fleshy fibers running between aponeuroses are relatively short whereas the aponeuroses are long and almost completely overlapping. Particularly in the second section, the most superficial fleshy fibers lie opposite the articulations between vertebrae rather than between successive transverse processes. These superficial fibers originate from a continuous sheet formed by aponeuroses of origin and insertion that run in opposite directions from a single transverse process. They insert on the medial surface of the outermost aponeurosis from the next anterior transverse process.

Because of the complexity of aponeuroses and differences in their number among the bellies of this series of muscles it is not feasible to designate individual aponeuroses by number. Rather, we shall refer to the group of aponeuroses of origin running primarily anteriorly as I, and the group of aponeuroses of insertion interdigitating with them as II; those portions of I and II attaching on the dorsal lateral tubercle and those on the ventral lateral tubercle are indicated by $\mathrm{d}$ and $\mathrm{v}$ respectively (see Figs. 9, 16). The fan-shaped, oblique aponeuroses of origin of $\mathrm{Mm}$. inclusi (of Boas, 1929) are designated III d and III v, attaching respectively on the lateral and medial sides of the costal pit. The horizontal aponeurosis of insertion of $\mathrm{Mm}$. inclusi attaching on the dorsolateral crest is termed IV $\mathrm{d}$, and the aponeurosis from the lateral crest, IV v.

Second section.-The structure of bellies of the second section is typically as follows: one or more aponeuroses of insertion (II) extend backward from the tubercles of the transverse process of the vertebra. The aponeuroses are flat, sheetlike and oriented vertically, the outermost presenting part of its surface in superficial view of the neck. One or more aponeuroses of origin (I) spring from the tubercles of the next transverse process, and run forward to interleave with the aponeuroses of insertion. Fibers ori- 
ginating on the lateral surface of the outermost of the Aponeuroses I insert on the medial side of the outermost Aponeurosis II. In combination with other aponeuroses of groups I and II the muscle forms a multipennate belly connecting successive transverse processes. Deep to this multipennate complex and partly continuous with Aponeuroses I d and I v are two fanshaped aponeuroses of origin (III $d$ and III $v$ ), the former attaching on the tuberculum costae and the latter on the medial edge of the costal pit. They extend anterodorsomedially toward the neural arch of the next anterior vertebra. These aponeuroses interleave with Aponeuroses IV d and IV $\mathrm{v}$ from the dorsolateral and lateral crests. Fibers originating from the lateral surface of III $d$ contribute to the multipennate complex of Aponeuroses I and II; fibers from its medial surface attach on the ventral surface of IV d, on the neural arch between the dorsolateral and lateral crests, and on the dorsal surface of IV v. Fibers from the dorsal surface of III $\mathrm{v}$ insert on the ventral surface of IV $\mathrm{v}$ just dorsal to the vertebral blood vessels. Aponeurosis IV d, attaching on the dorsolateral crest and continuing forward along the posterior edge of the transverse process, is reduced on vertebrae 10 and 11 to a ligamentous band curving posteromedially from the transverse process to the neural arch, where its attachment is indicated by a bony projection. The fibers associated with aponeuroses III and IV run primarily from the transverse process to the neural arch rather than between successive transverse processes, and thus correspond to $\mathrm{Mm}$. inclusi dorsalis and ventralis of Boas (1929: 177). The anterior belly of the inclusi series inserts on 9 and the posterior belly on 17; presence of the inclusi is usually reflected by the development of lateral and dorsolateral crests.

Occupying the lateral surface of the body of the vertebra ventral to the attachment of the inclusi is the large Part A of $M$. longus colli ventralis. Its fibers converge from their fleshy origin on the vertebra to attach on a lan-like extension of the main insertion tendon of the longus colli just before it crosses the anterior sublateral crest to insert on the postlateral process of the next vertebra anterior. Ventral fibers of the intertransversarii run parallel with and superficial to this tendon, but make their attachment on the transverse process lateral to the insertion of the longus colli.

A typical belly of the first section differs from that of the second section in that the aponeuroses of origin and insertion (I and II) are more numerous, slender, and horizontally oriented, thus exposing the multipennate nature of the muscle in superficial view. The inclusi portion is lacking, the lateral surface of the neural arch instead being occupied by $\mathrm{Mm}$. intercristales. Part A of $M$. longus colli ventralis is also absent. The muscle associated with vertebra 9 is intermediate between those typical of the 
first and second section in most respects. In the first section, an aponeurosis of origin ( $\mathrm{I} \mathrm{d}$ ) interdigitates with two corresponding aponeuroses (II d and II v). In addition fibers insert on a sheetlike extension of aponeurosis II $\mathrm{v}$ running back from the inner surface of the rib. The intertransversarii are bounded dorsally by broad aponeuroses of origin serving also the intercristales and ascendentes cervicis muscles. Anteriorly the bellies become smaller as they are crowded by the progressively larger intercristales and ascendentes cervicis muscles.

The belly connecting 5 and 4 runs forward from the ventral surface of the aponeurosis of origin of $\mathrm{Mm}$. ascendentes cervicis and from the dorsal surface of an aponeurosis extending forward from the dorsal rim of the vertebrarterial canal, to insert fleshily on the postero-dorsal surface of the transverse process. Fibers from aponeuroses bounding the vertebrarterial canal dorsally and ventrally extend forward to occupy the well-defined surface depression of the centrum leading into the canal of 4 , and the dorsal surface of rib 4 . The belly between 4 and 3 is similar but smaller. Aponeurotic fibers from the anterior edge of transverse process 3 insert on the lateral surface of 2 between the rib and the attachment of the intercristalis. The belly to the lateral edges of the atlas runs directly forward from transverse process 3 and is partly covered by the anteriormost slip of the ascendentes cervicis.

In addition to the basic structure described above for muscles of the first section, the superficial aponeurosis I $\mathrm{v}$ extends forward beyond the next transverse process and sends fibers forward spanning several vertebrae. This longer slip receives fibers from more than one vertebra before inserting by an aponeurosis on the cervical rib. The most posterior of these longer slips originates from vertebrae 10 and 9 and inserts on 8; the most anterior originates on $7,6,5,4$, and 3 and inserts on the rib of the axis. The pattern of slips, subject to some individual variation, is as shown in Figure 16A. The shorter slips among those inserting on a given vertebr: attach on the tip of the rib via a superficial aponeurosis. (Deep to this aponeurosis the tendon of the longus colli also attaches near the tip of the rib or along its ventral edge.) Longer slips have their insertion chiefly on a separate slender aponeurosis attaching on the anteroventral edge of the rib (Figs. 16B, 17A). The fibers of the intertransversarii and longus colli muscles are difficult to distinguish at their common insertions on the cervical ribs. Anteriorly the long ventral slips of the intertransversarii are covered by $M$. flexor colli brevis and $M$. rectus capitis superior.

In the third neck section the intertransversarii muscles tend to separate into distinct portions, one joining successive dorsal tubercles and the other successive ventral tubercles. In the belly between 16 and 15 , a broad 

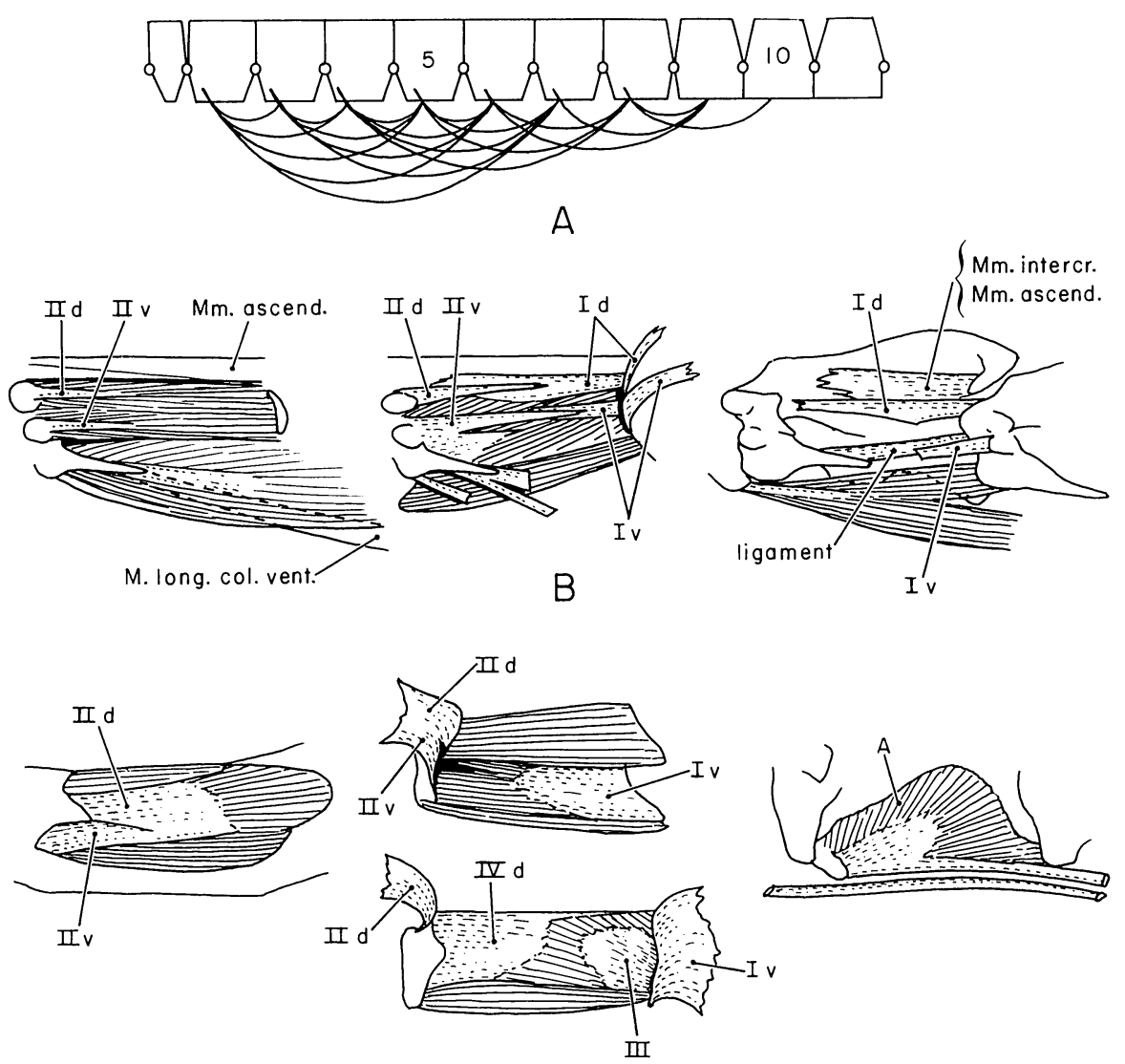

C
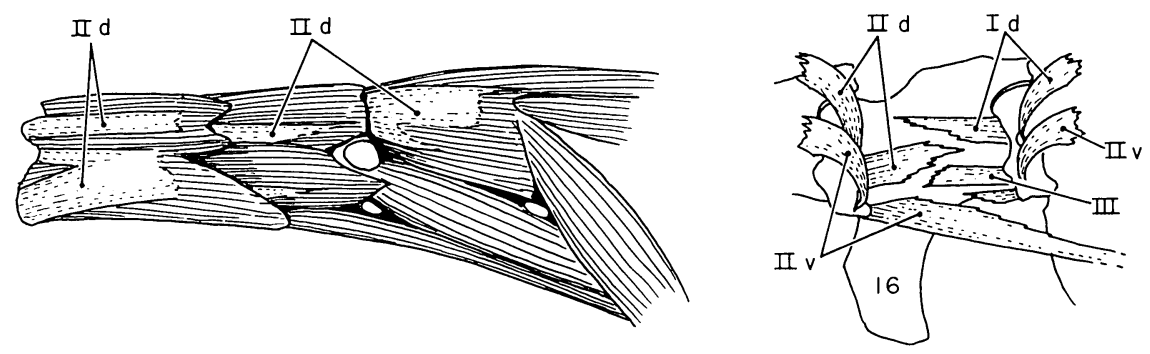

D

Fig. 16. Mm. intertranswersarii in Podilymbus. A. Diagram of ventral slips of first section inserting on ribs. B. Progressive dissection of muscle joining vertebrae 5 and 6 (section I). C. Progressive dissection of muscle joining vertebrae 12 and 13 (section II). Right figure shows Part A of $M$. longus colli ventralis and one additional tendon after removal of $\mathrm{Mm}$. intertransversarii. D. Left, superficial muscles connecting vertebrae 15-16, 16-17, and 17-18 (section III). Right, aponeuroses of vertebrac 16-17. Aponeuroses indicated by broken line shading. 
vertical aponeurosis (II), attaching between the lateral tubercles and the costal process of 15 , receives fibers from two complexes of aponeuroses (I) extending forward from the costal process, the lateral tubercles, and the transverse process of 16. Aponeuroses of origin from the lateral tubercles have a horizontal orientation and send fibers as well to the posterior surface of the transverse process of 15 . Fleshy fibers attach on the costal pit of 16, surrounded by Aponeuroses I and III.

Aponeurosis III sends fibers to the lateral surface of 15 between the vertebral blood vessels and the fan-like belly (A) of $M$. longus colli ventralis.

The dorsal part of the belly from 17 to 16 contains a horizontal aponeurosis (I d) from the anterior edge of transverse process 17 which sends fibers from its ventral surface to the posterior surface of the transverse process of 16, and to the dorsal surface of a horizontal aponeurosis (II d) attaching on the roof of the vertebrarterial canal of 16 . The ventral part consists of an aponeurosis (I v) from costal process 17 and a contiguous aponeurosis (III). Aponeurosis I v lies between Aponeurosis II d and II v of vertebra 16 and sends fibers to both. Aponeurosis II v of 16 receives a series of longer compact slips in the form of a large fan-shaped belly from 17 through 21 as follows: from aponeuroses extending forward from the ventral surface of the centrum of 17 , from the infralateral processes of 18 and 19, and from the lateral flange at the tips of the hypapophyses of 20 and 21.

Bellies of the intertransversarii from 18 to 17 and 19 to 18 are basically like that from 17 to 16 . M. inclusi, however, is reduced between 18 and 17, and absent between 19 and 18. Between 20 and 19 only the dorsal portion of the muscle is present, consisting of fibers running directly from the horizontal aponeurosis on the transverse process of 20 to the tranverse process of 19 , and fibers running from a pocket in the aponeurosis of 20 anterolaterally to insert on the tip of the transverse process of 19 .

The posterior belly representing Part A of $M$. longus colli ventralis, originates from 16. It is very small and attaches on the ventrolateral surface of the centrum.

These complex muscles are basically similar in $P$. gigas but they are more powerfully constructed. All aponeuroses exposed to superficial view in podiceps are occupied by muscle fibers in gigas.

M. longus colli ventralis (Figs. 11, 16, 17, 19) is the major muscle lying on the ventral surface of the neck between the paired intertransversarii muscles. The muscle as a whole extends from vertebra 2 to 21 , with the bulk of its fleshy fibers lying posteriorly. It consists of an overlapping series of bellies each of which has more than one slip. The general relationships of slips and bellies are shown in Figure 17. 


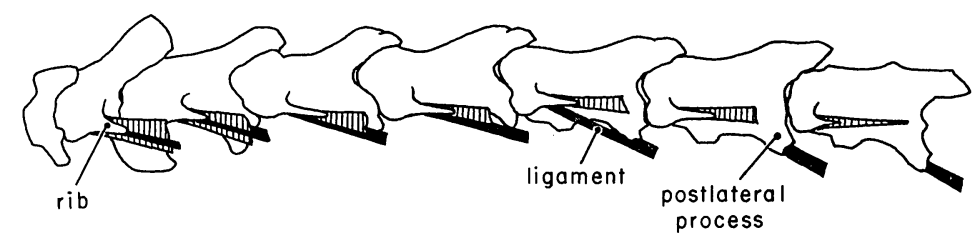

A
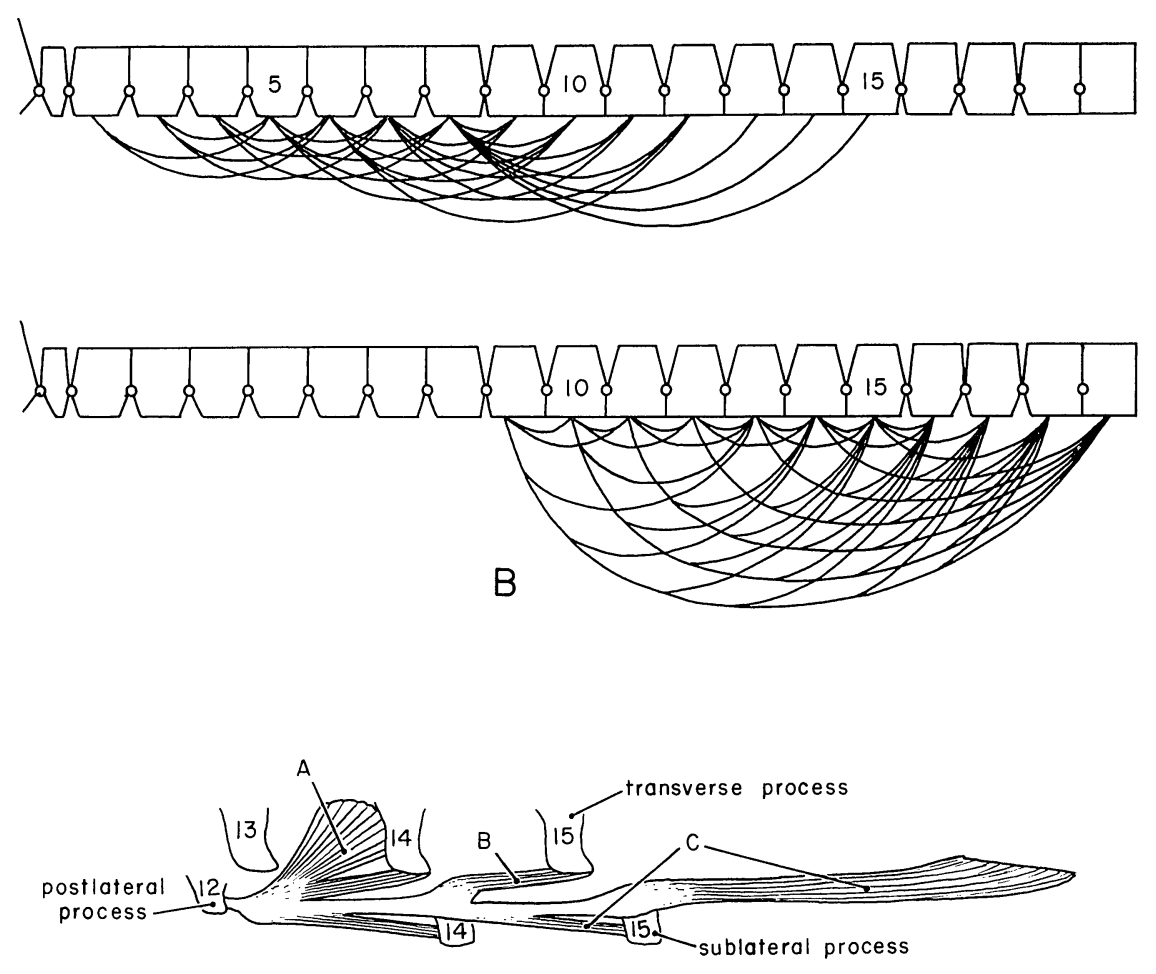

C

Fig. 17. M. longus colli ventralis in Podilymbus. A. Diagram of aponeurotic attachments of longus colli (black) and intertransversarii muscles (cross-hatched) on ribs and postlateral processes. B. Diagram of slips of longus colli: slips to section I above; slips to section II below. C. Diagrammatic drawing of a single slip of the longus colli muscle showing its parts, Abbreviation: proc.-process. 
Origin of fleshy slips is primarily from the hypapophyses and sublateral processes and from the lateral surfaces of the centra. Because the bellies form an overlapping series, slips belonging to different bellies originate from each hypapophysis or sublateral process. For any one belly, the slips originating on different vertebrae extend forward, each slip lying ventral and medial to those originating anterior to it, to insert in sequence on the ventral surface of a long narrow flattened aponeurosis. In section two the aponeurosis of insertion typically attaches on the postlateral process after crossing the anterior sublateral crest of the vertebra posterior to that of insertion. The anterior sublateral crest is flattened and smooth in vertebrae of the second section in relation to its function of support for the tendons of insertion.

On vertebrae in which a rib is well developed (2 through 6 of the first section), slips of this muscle insert by a tendon on the rib and have little or no attachment on the postlateral process. On 5, the inserting tendon has a partially tendinous attachment to the postlateral process in addition to its main attachment on the rib; in vertebra 6 , the tendon has a strong attachment on the postlateral process, but continues on as well to the tip of the rib. The insertion on more posterior vertebrae is tendinous on the postlateral process alone.

Bellies of the first section are relatively short and of nearly equal length, spanning five (or six) vertebrae. Insertions of the first five bellies are on the ribs, in company with the ventral slips of the intertransversarii (see p. 39), and the tendons of insertion are relatively slender. The slips originate from sublateral processes. The anteriormost fibers of a belly arise from the second vertebra posterior to the vertebra of insertion.

Bellies inserting on the second section have more complicated origins than those just described. The long tendons of insertion receive slips originating from the sublateral processes or hypapophyses of the second vertebra posterior to that of insertion, and from successively more posterior vertebrae. In addition each inserting tendon (on vertebrae 8 through 16) receives a fan-shaped slip (Part A) from the centrum and sublateral crest of the vertebra immediately posterior to it. Additional slips (Part B) from the transverse process and rib process of the second and third vertebrae posterior to the insertion of the main tendon are received on small lateral wings of the main tendon (Fig. 17C).

A typical belly of the second section thus consists of a long flat tendon receiving its main bulk of fibers posteriorly through slips from hypapophyses, and receiving smaller slips along its medial edge from sublateral processes (Part G); a stout slip (Part A) from the body of the vertebra posterior to the insertion, and sometimes a small slip (Part B) along its 
lateral edge from several transverse processes. The bellies associated with vertebrae 7 and 8 are morphologically transitional between those of the first and second sections.

The longus colli ventralis of gigas closely resembles that of podiceps.

M. flexor colli profundus (Figs. 18, 19), lying deep on the anteroventral portion of the neck, is a series of bellies that could be regarded as a forward continuation of certain elements of the longus colli ventralis. We consider the posterior belly to consist of those slips inserting on the postlateral process of vertebra 6 , where the longus colli muscle changes its point of insertion from the postlateral process (as on 7 ) to the cervical ribs. (The tendon of insertion of $M$. longus colli ventralis is partly bound to the postlateral processes of 6 and 5 .)

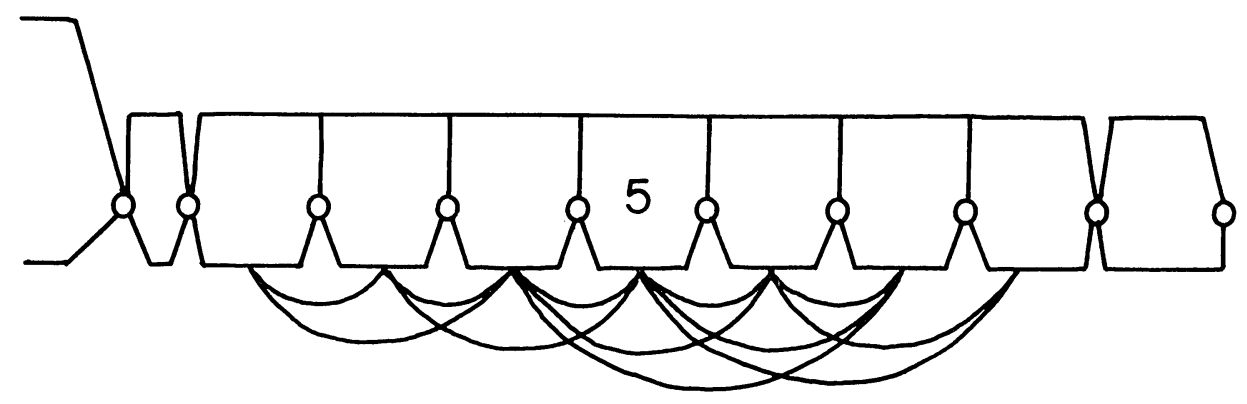

Fig. 18. Diagram of $M$. flexor colli profundus in Podilymbus.

A belly inserts on the postlateral process on each vertebra from 6 through 3 , and on the lateral and posterior surfaces of hypapophysis 2. The postlateral process of 6 and a short aponeurosis extending back from it receive a slip originating from the ventrolateral edge of the transverse process of 8 , and also slips from the sublateral process and a small aponeurosis of 8 and from the postlateral process of 7 . Bellies to 5 and 4 are similar to 6 . The belly to 3 originates from the costal process and sublateral crest of 5 and the postlateral process of 4 . The anteriormost belly to the axis arises from the costal process of 4 , and the postlateral process, and sublateral crest and process of 3 .

This muscle is similar in $P$. gigas.

Discussion.--The cervical vertebrae and muscles of Podilymbus podiceps and gigas differ only slightly. The neck of gigas is relatively more powerful than podiceps, as indicated by better development of crests and processes, greater massiveness of neck muscles, larger aponeuroses, and more extensive occupation of aponeurotic surfaces by fleshy fibers. In gigas there 

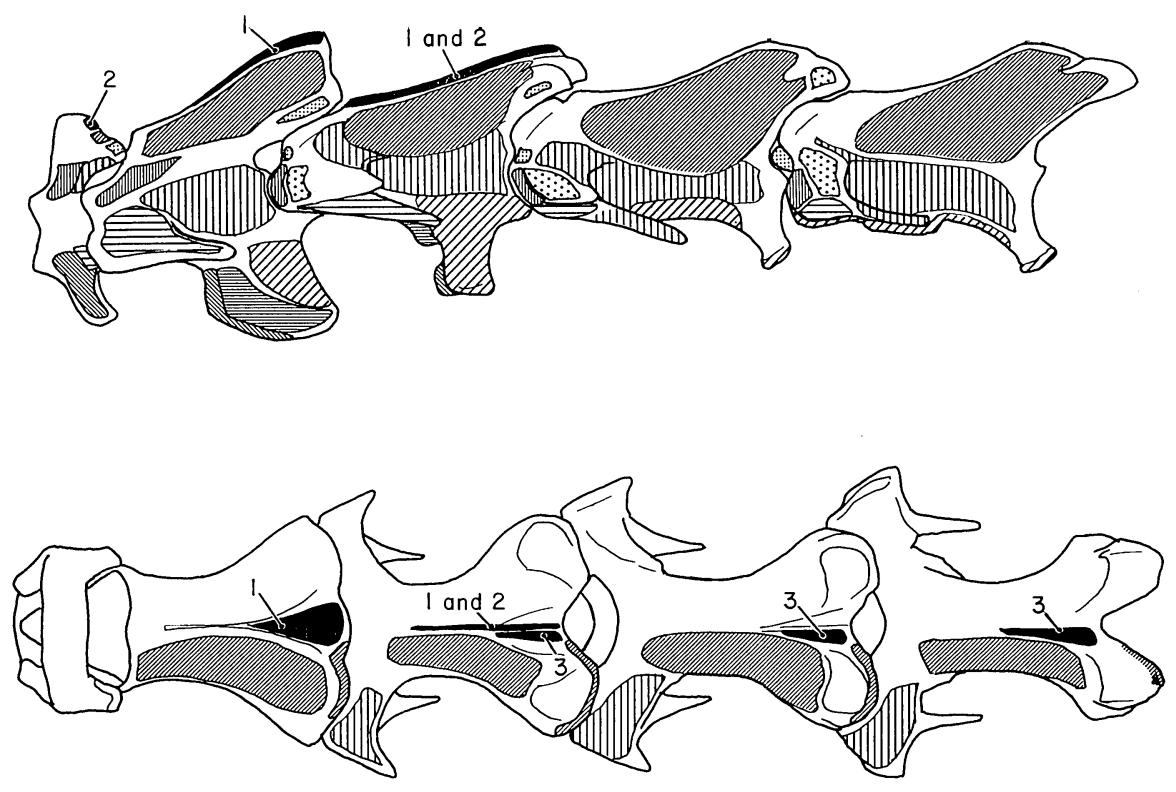

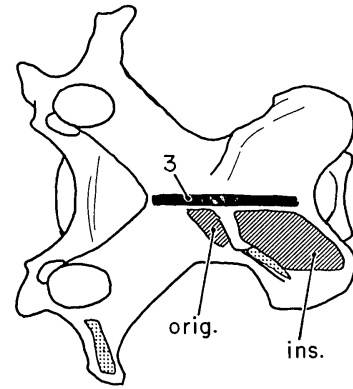

13

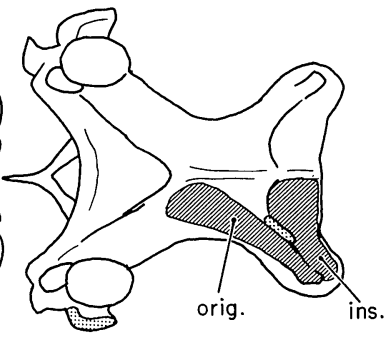

15

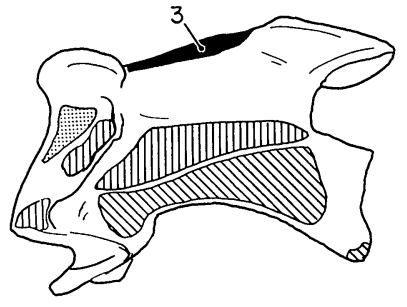

II

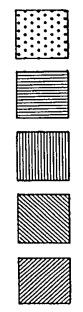

M. complexus (origin)

M. rec. cap. lat. (origin)

M. rec. cap. sup. (origin)

M. rec. cap. vent., anteromed. portion

Mm. intercr.

M. spl. cap. - I

M. spl. ant. -2

M. spl. col. -3

Fig. 19. Attachments of cervical muscles on anterior vertebrae from lateral view (above) and dorsal view (middle), and on selected vertebrae of section II (below). Abbreviations: ant.-anterior, ascend.--ascendentes, brev.-brevis, cap.-capitis, cerv.-cervicis, col.colli, flex.-flexor, intercr.-intercristales, intertr.-intertransversarii, lat.-lateralis, long.longus, M.-Musculus, Mm.-Musculi, prof.-profundus, rec.-rectus, spl.-splenii, sup.superior, vent.-ventralis. 
is an additional slip on the posterior end of the complexus muscle.

Boas (1929) described the splenii colli and longus colli ventralis muscles of Podiceps cristatus. Of these, the first is evidently similar to Podilymbus; the second is also basically similar except that the transition from insertion on rib to insertion on postlateral process takes place in vertebrae 8 and 9 rather than in 5 and 6 , as in Podilymbus. In both genera there is a ligamentous connection between the tip of the rib and the postlateral process in each of the transitional vertebrae. $P$. cristatus has its last large rib on 8, and a much smaller one on 9; Podilymbus has its last rib on 7 . The ribs serve for the attachment of the intertransversarii as well as the longus colli and the presence of a rib does not therefore indicate an attachment of the longus colli on that rib. The change in place of insertion of the longus colli occurs at the junction of neck sections I and II, as does change from long to short slips, in Podiceps cristatus. In Podilymbus the change from long to short slips also coincides with the junction of the neck sections but the change in place of insertion lies well within section I, and anterior to the last rib.

\section{CONCLUSIONS}

Comparison of the head and neck in Podilymbus podiceps and P. gigas reveals a close similarity in conformation, structure, and interrelationships of bones and muscles in the two species. The most striking differences are the greater massiveness of jaw, neck, and hyoid muscles in gigas, and the occupation of all aponeurotic sheets superficial in podiceps (adductor mandibulae and intertransversarii muscles) by muscle fibers in gigas. That the stout, decurved bill enables Podilymbus podiceps, and especially gigas, to include large crustaceans in their diets was suggested above. The relatively more powerful neck and jaw musculature of gigas may also represent adaptations for dislodging and crushing crustaceans. As mentioned earlier, a native crab occurs in Lake Atitlán whereas fish may have been introduced by man. Both species of Podilymbus include fish in their diets; although their structural specializations are not for fish-catching, the specializations are not so extreme that fish-catching is excluded.

The species of Podilymbus are better able to manipulate, tear, and crush large prey than slender-billed forms, but they apparently open the bill less forcefully than other grebes (except Tachybaptus), to judge from the poor leverage of the depressor mandibulae in Podilymbus (and Tachybaptus). Leverage is greatest in Aechmophorus, and the depressor may serve in that species to hold a fish by forcibly opening the jaws after spearing the body of the fish with closed mandibles (see Lawrence, 1950:13).

Comparison of Podilymbus with published descriptions of Podiceps 
cristatus reveals differences in structure of $M$. pseudotemporalis superficialis, $M$. adductor mandibulae, and $M$. longus colli ventralis, as well as differences in proportion and shape of many parts of the head and neck. The postorbital process is differently placed (see below). The functional and taxonomic importance of these differences will become clear only through detailed comparative studies of more species of grebes. Some points of potential interest for further studies are discussed below.

The postorbital ligament generally lies in a position approximately perpendicular to the closed lower jaw and attaches on the jaw just anterior to the quadrate's mandibular articulation; the location of the postorbital process on the skull is usually dictated by the position of the ligament, regardless of the shape of the skull or extent of jaw muscles. The postorbital process lies in its expected position with respect to the lower jaw in Tachybaptus (ruficollis), Rollandia (rolland, micropterum), and Podiceps (major, dominicus, grisegena, cristatus, auritus, nigricollis), despite differences among these species in the shape of the cranium and in the position of the process with respect to the cranium. In Podilymbus and Aechmophorus the postorbital process lies anterior to its expected position with respect to the lower jaw. The postorbital ligament of Podilymbus angles backward and is bound to the zygomatic process, but it then continues ventrally at right angles to the lower jaw. The postorbital ligament therefore apparently serves the same functional roles in Podilymbus as in Podiceps, Rollandia, and Tachybaptus, and the forward shift of the process may reflect a functional relation to the periocular ligament instead.

Comparison of the muscle scars and crests associated with M. pseudotemporalis superficialis in many species of grebes suggests that considerable variation occurs in this muscle within the family, but nothing is known of the adaptive or taxonomic significance of such variation.

In grebes a part of $M$. adductor mandibulae originates behind the cranium from the complexus and from a medium raphe. In Aechmophorus the raphe is partly ossified, forming a sagittal crest. An analogous development can be seen in Sula, and a greater specialization in Phalacrocorax and Anhinga, in which part of the adductor mandibulae attaches on an occipital style lying over the neck muscles. In all of these birds the need for powerful adduction as well as streamlining of the head may explain the posterior spread of the adductors, but the effects of streamlining of the head on the structure of jaw muscles are not well known.

In grebes the longus colli ventralis attaches on the postlateral processes of the second neck section and transfers its attachment to the ribs in the first neck section. Variability in the point of transfer should be studied, as should the functional significance of the different attachments. Attach- 
ment on the postlateral process can be recognized in a skeleton by the enlargement of the process and by the lack of a cervical rib. In the attachment of this muscle on the postlateral process, grebes differ from the Gaviidae, Hesperornithidae, and Heliornithidae, to which they have been allied by various authors; in this character they differ, in fact, from all other birds except the Rhinochetidae, Eurypygidae, and Rheidae. The significance of this type of longus colli is unknown, and its presence in rheas probably has no phylogenetic connection with its presence in grebes. The possibility of the grebes being clerived from one of the ancient gruiform stocks should be investigated further.

\section{LITERATURE CITED}

BAms, R. A. 1956. On the Relation between the Attachment of Jaw Muscles and the Surface of the Skull in Podiceps cristatus L., with some notes on the Mechanical Properties of this Part of the Head. Proc. K. ned. Akad. Wet. Amsterdam, Ser. C, 59: 82-101; 248-262.

BARNikol, A. 1952. Korrelationen in der Ausgestaltung der Schädelform bei Vögeln. Morph. Jb., 92: 373-414.

Beddard, Frank E. 1896. On the Anatomy of a Grebe (Aechmophorus major), with Remarks upon the Classification of some of the Schizognathous Birds. Proc. zool. Soc. Lond., 1896: 538-547.

1898. The Structure and Classification of Birds. London: Longmans, Green and Co.

Bons, J. E. V.. 1929. Biologisch-Anatomische Studien über den Hals der Vögel. K. danske Vidensk. Selsk. Skr., Naturvid. Math. Afd., 9, vol. 1, pp. 105-222, 23 pls.

Bowes, Anne I.aBAstille. 1965. An ccological investigation of the Giant Pied-billed Grebe, Podilymbus gigas Griscom. Bull. Br. Orn. Club, 85: 14-19.

Bowes, Anne Labastille, and C. V. Bowes, Jr. 1962. Recent Census and Observations of the Giant Pied-billed Grebe of Guatemala. Auk, 79: 707-709.

Engels, William L. 1938. Tongue Musculature of Passerine Birds. Auk. 55: 642-650.

Gabrielson, Ira N. 1914. Pied-billed Grebe Notes. Wilson Bull., 26: 13-15.

Hofer, Helmut. 1950. Zur Morphologie der Kiefermuskulatur der Vögel. Zool. Jb., 70: $427-556$.

LAKJer, Tage. 1926. Studien über die Trigeminus-versorgte Kaumuskulatur der Sauropsiden. Kopenhagen: C. A. Reitzel Buchhandlung.

Lawrence, Grorge: E. 1950. The Diving and Feeding Activity of the Western Grebe on the Breeding Grounds. Condor, 52: 3-16.

Millfer, Richard F. 1943. The Pied-billed Grebe, A Breeding Bird of the Philadelphia Region. Cassinia, 32: 22-34. 
Miller, Robert Rush. 1955. A Systematic Review of the Middle American Fishes of the Genus Profundulus. Misc. Publs. Mus. Zool. Univ. Mich., 92, 64 pp., 9 pls.

Munro, J. A. 1941. The Grebes. Studies of Waterfowl in British Columbia. Occ. Pap. Br. Columb. prov. Mus. 3, 71 pp.

Saunders, George B., Ancil D. Holloway, and Charles O. Handley, Jr. 1950. A Fish and Wildlife Survey of Guatemala. Spec. scient. Rep. U.S. Fish wildl. serv. Wildlife No. 5, 162 pp.

Shufeld, R. W. 1890. Contributions to the Comparative Osteology of Arctic and Sub-arctic Water-Birds. Part VI. J. Anat. Physiol., Lond., 24: 169-187.

1904. On the Osteology and Systematic Position of the Pygopodes. Am. Nat., 38: $13-49$.

Simonetta, Alberto M. 1963. Cinesi e morfologia del cranio negli uccelli non passeriformi. Archo zool. ital., 48: 53-135.

Storer, Robert W. 1963. Courtship and Mating Behavior and the Phylogeny of the Grebes. Proc. XIII Int. Orn. Congress: 562-569.

Trautman, Milton B. 1940. The Birds of Buckeye Lake, Ohio. Misc. Publs. Mus. Zool. Univ. Mich., 44, 466 pp.

Wetmore, Alexander. 1924. Food and Economic Relations of North American Grebes. Dept. Bull. U.S. Dep. Agric. 1196, 23 pp.

Wetmore, Alexander, and Kenneth C. Parkes. 1954. Notes on the generic affiliations of the great grebe of South America. J. Wash. Acad. Sci., 44: 126-127.

Zusi, Richntd L. 1962. Structural Adaptations of the Head and Neck in the Black Skimmer Rynchops nigra (Linnaeus). Publs. Nuttall orn. Club, No. 3: viii +101 pp., 44 text figs. 


